\title{
The impact of review valence and awareness of deceptive practices on consumers' responses to online product ratings and reviews
}

\author{
Ismail Karabas \\ Murray State University, ikarabas@murraystate.edu \\ Ioannis Kareklas \\ University at Albany, State University of New York \\ T. J. Weber \\ California Polytechnic State University, San Luis Obispo \\ Darrel D. Muehling \\ Washington State University
}

Follow this and additional works at: https://digitalcommons.murraystate.edu/faculty

Part of the Marketing Commons

\section{Recommended Citation}

This is an Accepted Manuscript of an article published by Taylor \& Francis in Journal of Marketing Communications on May 5, 2020, available online: https://www.tandfonline.com/doi/full/10.1080/ 13527266.2020.1759120.

This Peer Reviewed/Refereed Publication is brought to you for free and open access by Murray State's Digital Commons. It has been accepted for inclusion in Faculty \& Staff Research and Creative Activity by an authorized administrator of Murray State's Digital Commons. For more information, please contact msu.digitalcommons@murraystate.edu. 
The Impact of Review Valence and Awareness of Deceptive Practices on Consumers' Responses to Online Product Ratings and Reviews

\author{
Ismail Karabas $^{\mathrm{a}^{*} \text {, Ioannis Kareklas }}{ }^{\mathrm{b}}$, T.J. Weber ${ }^{\mathrm{c}}$, and Darrel D. Muehling ${ }^{\mathrm{d}}$ \\ ${ }^{a}$ Department of Management, Marketing, and Business Administration, Murray State University, \\ U.S.A.; \\ ${ }^{b}$ Department of Marketing, University at Albany, State University of New York, Albany, New \\ York, U.S.A.; \\ ${ }^{c}$ Marketing Area, Orfalea College of Business, California Polytechnic State University, San Luis \\ Obispo, U.S.A.; \\ ${ }^{d}$ Department of Marketing and International Business, Carson College of Business, Washington \\ State University, Pullman, U.S.A.
}

*The corresponding author can be contacted via email at ikarabas@ murraystate.edu or by phone at (270) 809-6206.

Ismail Karabas is an Assistant Professor of Marketing at the Department of Management, Marketing, and Business Administration, Murray State University, Murray, KY.

Ioannis Kareklas is an Assistant Professor of Marketing at the University at Albany, State University of New York, Albany, New York, U.S.A.

T.J. Weber is an Assistant Professor of Marketing at the Orfalea College of Business, California Polytechnic State University, San Luis Obispo, California, U.S.A.

Darrel Muehling is a Professor of Marketing at the Carson College of Business, Washington State University in Pullman, Washington, U.S.A. 


\title{
The Impact of Review Valence and Awareness of Deceptive Practices on Consumers' Responses to Online Product Ratings and Reviews
}

\begin{abstract}
Many online retailers and some manufacturers/service providers have recently been engaging in questionable practices, where product reviews are often fabricated and/or posted without sufficient clarity and objectivity. Across an exploratory study and two main studies, we empirically examine this phenomenon and observe a pattern of effects that suggests that review valence (i.e., the average number of rating-stars a product receives) influences product attitudes and intentions, but that these outcomes are significantly impacted by the extent to which consumers are aware of potentially deceptive online review practices. Awareness of deceptive practices was found to differentially influence attitudes and intentions, depending upon whether the star-ratings were perfect ( $5 / 5$ stars), highly positive $(4.9 / 5$ stars), or generally positive $(4.5 / 5$ or 4.7/5 stars). Participants' perceptions of the e-retailer's manipulative intent were also shown to mediate these effects, with higher perceptions of perceived manipulative intent yielding less favorable product attitudes and reduced purchase intentions.
\end{abstract}

Keywords: online retailing; electronic word-of-mouth (eWOM); review valence; deceptive online product ratings; manipulative intent; persuasion knowledge 
Ample empirical evidence suggests that word-of-mouth (WOM) can impact what consumers "know, feel, and do" in the marketplace (Buttle 1998, 241), and can have a greater impact on resulting purchase behavior than marketer-controlled sources of information (Buttle 1998). More recently, as consumers have shifted their purchasing from brick-and-mortar to online retail stores, consumer-generated electronic word-of-mouth (eWOM) has become an increasingly important pre-purchase information source (e.g., Belanche, Flavian, and PerezRueda 2020; Kuo and Nakhata 2019; Roy, Datta, Mukherjee 2019; You, Vadakkepatt and Joshi 2015). In fact, a study on new product diffusion comparing WOM and eWOM finds that "peak sales rate and cumulative sales at peak time" are highest through eWOM, as compared to traditional offline WOM (Huang et al. 2014, 178).

As online shopping continues to grow in popularity, so too has the importance of online product reviews. For example, a report by Mathwick and Mosteller (2017) notes that 30\% of consumers in the U.S. begin their online search for product and service information by reading customer reviews on e-retailer sites such as Amazon.com. Furthermore, according to the Pew Research Center, $82 \%$ of adults read reviews at least sometimes before making online purchases, with $40 \%$ saying they always or almost always do so (Smith and Anderson 2016). For retailers, eWOM has become an increasingly important factor driving sales (as compared to more traditional marketing techniques), likely because of: (a) its lower costs, (b) higher interactivity, (c) greater speed of dissemination, and important to our investigation, (d) its perceived lack of commercial bias (Raassens and Haans 2017).

Given the increased emphasis on eWOM in the consumer decision making process, it is perhaps not surprising, to find online retailers and some manufacturers and service providers electing to engage in practices that challenge the boundaries of established ethical norms 
(Anderson and Simester 2014; Baker 2017; Beaton 2018; Moriuchi 2018; Patel and Siu 2019; Swearingen 2019; Walsh 2019). These practices range in form from posting outright "fake" reviews, to ones where the manufacturer and/or retailer has incentivized reviewers, with hopes of garnering more favorable (and perhaps, less objective) evaluations of the promoted product or service. In the current study, our focus is primarily on online practices that have the potential to unfairly influence consumers' purchase decisions. The most common practices include some combination of: (a) offering products or services free-of-charge to consumers who tend to post a high volume of reviews in exchange for their continued willingness to post additional product/service reviews (with the assumption that these reviewers will, in kind, post largely favorable reviews); (b) re-posting large volumes of (typically highly favorable) reviews that originate from manufacturers' websites, where less-favorable reviews are omitted, and mostly favorable reviews are retained; (c) directly paying reviewers to post positive product/service reviews, with the hopes of a quid pro quo; and (d) allowing manufacturers, publishers, writers, or other third parties to post fabricated promotional online reviews (Mayzlin, Dover, and Chevalier 2014).

Perhaps surprisingly, even with what would be expected to be broad media coverage of the topic, a recent study of consumers' awareness of "fake" reviews on the Amazon.com website indicated that a majority of consumers were generally unaware of such practices (Sterling 2019). Similarly, the December 19, 2019 broadcast of the NBC Nightly News (NBC 2019) included a segment on "how to spot fake product reviews online" - likely designed to educate and inform unwitting consumers about the presence of potentially deceptive online reviews.

Another disturbing trend in recent years has been the proliferation of so called "reputation management software." A simple web search for this term will bring up dozens of 
such services that are now available to manufacturers and e-retailers to help them manage their online reviews. The widespread use of such services is troubling, as these providers (e.g., "ReputationLoop," "Grade.US," "Reputation Engagement Suite," etc.) promise to generate a greater number of more positive customer reviews; some even go as far as to promise to "promote the positive" and "bury the negative" online consumer reviews (Reputation Defender 2018). Additionally, while not deceptive in nature, "affiliate marketing" programs may be considered a related practice to the aforementioned online review practices, as they may also yield inauthentic product reviews. Such marketing programs involve affiliates receiving products free-of-charge from manufacturers, with the understanding that they will then post favorable reviews of these products (often on their personal YouTube channels), and earn a commission each time consumers on the affiliate site click links to the merchant's e-commerce site resulting in a sale (Edelman and Brandi 2015; Zax and Zax 2017). While such programs are not illegal and should not be directly equated to some of the aforementioned practices (such as posting completely fabricated reviews), they nonetheless create similar challenges for consumers trying to ascertain the true/unbiased value of featured products.

The resulting effect of the deceptive and related practices outlined above is that a proliferation of more positive reviews may lead unwitting consumers to make suboptimal decisions, which may result in purchases they would not have otherwise made. For example, research suggests that on average, sponsored reviews tend to be more positive than organic reviews (Kim, Maslowska, and Tamaddoni 2019; Rynarzewska 2019; Stanton et al. 2019). Further, an analysis of seven million Amazon reviews revealed that incentivized reviews were four-tenths of a star greater than their non-incentivized counterparts (ReviewMeta 2016). While the exact scale of manipulated online review practices is difficult to gauge, their potential impact 
is difficult to deny, given their ability to impact consumers' purchase considerations and lead to product preferences which may not have otherwise occurred.

In addition to potentially making suboptimal product choices because of being influenced by "manipulated" reviews, these e-retailer practices may also lead consumers to mistrust honest and unbiased reviews (Mayzlin, Dover, and Chevalier 2014), which could have additional adverse effects for both e-commerce and consumer welfare. Given the potential for consumer deception, e-retailers and manufacturers engaging in online review practices of this type are also likely to come under greater legal scrutiny in the future. For example, the FTC has recently accused a marketer (Cure Encapsulations, Inc.) of paying a third-party website owner to write and post fake reviews on Amazon.com (FTC 2019). Thus, it is critical for online retailers to understand the role of online information within the consumer decision making process, so they can build effective e-retail strategies (Hajli et al. 2015).

Additionally, posting fake reviews, which is often called "astroturfing," is illegal in the United Kingdom. Such practices fall under the Consumer Protection from Unfair Trading Regulations (CPUTR) of 2008, which regulate commercial practices deemed to be unfair in the UK (The UK Rules 2020). Posting fabricated online reviews are considered unfair commercial practices because they are believed to exhibit a great likelihood to distort the economic behavior of average consumers and may also violate laws pertaining to advertising codes (The UK Rules 2020).

In the present research, we are interested in better understanding how consumers respond to products that receive positive online reviews (hereby formulated as average star ratings), and the extent to which knowledge of deceptive online review practices alters subsequent purchase decisions. Our review of the literature suggests that the existence of deceptive review practices in 
the online marketplace is potentially problematic for consumers, manufacturers, and e-retailers, as the incentives underlying the review process may alter the utility of online reviews. This is likely to occur because offering reviewers free products or other incentives may generate undue positive affect unrelated to the product's true quality or features, but instead, is a function of reviewers' appreciation toward the e-retailer or manufacturer (Isen et al. 1978; Nguyen et al. 2019; Rynarzewska 2019; Stanton et al. 2019; Westbrook 1980). Therefore, it seems that these practices may artificially inflate product reviews, diminishing both their objectivity and usefulness for potential buyers. Considering this, the emergence of these potentially deceptive practices may shift the nature of online reviews from incentive-free user-generated content to a marketing tool purposefully manicured by e-retailers and manufacturers, potentially at the expense of consumers, as well as other e-retailers and manufacturers who do not engage in such practices.

\section{CONCEPTUAL DEVELOPMENT}

A central question of strategic importance in e-retailing is what makes an online review persuasive. Past research suggests that effective online reviews are driven by a combination of affective linguistic elements (Ludwig et al. 2013), source credibility cues (Kareklas, Muehling, and Weber 2015), inferences of manipulative intent (Weber, Kareklas, and Muehling 2019), exposure to reviews and price (Maslowska, Malthouse, and Viswanathan 2017), and the perceived valence and volume of consumer ratings (Chevalier and Mayzlin 2006; Tata, Presha, and Gupta 2020). In the present study, we focus on review valence, and consider the impact of source credibility, persuasion knowledge, and manipulative intent on consumer response to products appearing on e-retailer websites. 


\section{Review Valence}

Review valence refers to the "tone or preference" of eWOM, typically expressed in positive, negative, or neutral feedback for the firm, manufacturer, and/or other consumers (You, Vadakkepatt and Joshi 2015, 19). Summaries of valenced reviews are usually prominently placed in a table or chart between the brand name and the listed price, and often utilize star rating systems (typically out of a maximum of 5 stars), which is also how valence is operationalized in our investigations. Because of its prominent placement, valence is consistently found to be among the most salient and persuasive feature of online reviews (Blal and Sturman 2014; Flanagin and Metzger 2013; Floh, Koller, and Zauner 2013; Maslowska, Malthouse, and Bernritter 2017).

Although some mixed findings regarding the impact of review valence on consumer responses have been reported, specifically as it relates to potential moderators and/or ceiling effects (see, e.g., King, Racherla, and Bush 2014; Maslowska, Malthouse, and Bernritter 2016; Mudambi and Schuff 2010; Pan and Zhang 2011), ${ }^{1}$ past literature generally suggests that morepositively valenced reviews and review summaries lead to more favorable responses from customers, such as more positive attitudes and heightened purchase intentions (Chevalier and Mayzlin 2006; Gopinath, Thomas, and Krishnamurthi 2014; Lin and Xu 2017; Tata, Prashar, and Gupta 2020), and may ultimately lead to higher sales (Chevalier and Mayzlin 2006). For example, in a comprehensive meta-analysis of the domain of product reviews, Floyd et al. (2014) note that positive product reviews tend to be associated with more favorable product attitudes and enhanced expectations regarding product quality (see also: Purnawirawan et al. 2015). Thus, in line with the established evidence on the importance of eWOM and the effect of review

\footnotetext{
${ }^{1}$ The notion of a ceiling effect, i.e., whether a perfect 5 -star rating may be perceived by consumers as being "too high" and thus, less impactful, is one of the foci of our second study.
} 
valence on consumer decision making, we would expect to find a general linear relationship between online review valence and consumer responses - specifically, between review valence and attitudes and purchase intentions.

\section{Source Credibility}

In the present context, perceived credibility of eWOM communications (Fan et al. 2013) is defined as "the extent to which one perceives a recommendation/review as believable, true, or factual" (Cheung et al. 2009, 12). Of note, Reichelt, Sievert, and Jacob (2014) posit that the perceived credibility of eWOM communicators impacts the effectiveness of eWOM on message recipients' attitudes and behavioral intentions. Similarly, Cheung et al. (2009) find that the perceived credibility of online contributors on discussion forums significantly impacts the likelihood that readers will adopt eWOM recommendations.

It is important to clarify at this point that the current work does not assert that all reviews generated from a sponsored program are deceptive and/or manipulative in nature. In our introduction section we clearly delineated which e-retailer or manufacturer practices we consider to be potentially deceptive in nature and thus problematic (e.g., posting fabricated reviews), and which practices we consider to be more simply part of a manufacturer's promotional strategy (e.g., affiliate programs). While we note that affiliate programs may also lead to inauthentic reviews, it is difficult to determine when that is the case. Additionally, some consumers report that they find sponsored reviews useful, as they tend to be more elaborate and focused more on the product itself and less on external factors, such as excitement or anger regarding the purchase experience itself or the speed of delivery (Kim, Maslowska, and Tamaddoni 2019).

The problematic nature of deceptive online review practices for consumers is driven by the fact that products cannot be physically examined (e.g., felt, smelled) in online retail settings. 
Because of this, research suggests eWOM is weighted more strongly in consumer decisionmaking than more traditional media, such as newspaper reviews and paid media (Cheung and Thadani 2012), and is viewed as higher in "credibility, empathy, and relevance to customers than marketer-created sources of information on the web" (Gruen, Osmonbekov, and Czaplewski 2006, 449).

One explanation for why consumers consider online reviewers to have higher credibility than other information sources is perceived similarity to themselves, as the consumer and reviewer share an obvious interest in the product or service in question (Zhang 2015). Further, because consumers cannot physically evaluate a product online, implicit trust of strangers is a prerequisite for consumers making decisions online (Pan and Chiou 2011). However, some recent evidence suggests that consumers are becoming more skeptical of information obtained through eWOM, specifically questioning the trustworthiness and credibility of the information provider, when they suspect that s/he may have other ulterior motives (Mathwick and Mosteller 2017). As a consequence, persuasion knowledge and perceived manipulative intent are expected to influence consumers' judgments.

\section{Persuasion Knowledge and Manipulative Intent}

The "persuasion knowledge model" suggests consumers use their knowledge of marketing to form theories about persuasion that includes "beliefs about marketers' motives, strategies, and tactics; effectiveness and appropriateness of persuasion tactics; psychological mediators of tactic effectiveness; and ways of coping with persuasion attempts" (Campbell and Kirmani 2000, 69). In addition, this model suggests that consumers' use of persuasion knowledge is driven by two factors: (a) the accessibility of ulterior motives, and (b) the cognitive capacity of the consumer (Campbell and Kirmani 2000). The model further proposes that when 
consumers deduce ulterior motives on behalf of the marketer and have the necessary cognitive resources to process these motives, they will infer an underlying persuasion motive termed “manipulative intent” (Campbell 1995).

This well-accepted model is designed to explain consumer-firm interactions when the consumer infers ulterior motivation on behalf of the persuader (Campbell 1995) and would appear to be applicable to promotional strategies involving deceptive online consumer reviews. As such, we propose that if consumers are generally aware of these deceptive practices when evaluating online reviews, ulterior motives are more likely to be inferred (Li and Hitt 2008). Such inferences are likely to damage the perceived authenticity, believability, and credibility of online reviews, especially when they are extremely positive, in which case they may be deemed to be less realistic, as perfect review scores are less likely to occur organically (Bosman, Boshoff, and van Rooyen 2013; Maslowska, Malthouse, and Bernritter 2017; Mudambi and Schuff 2010; O'Reilly and Marx 2011). This points to a non-linear effect of review valence, with the positive effect of review valence in part characterized by diminishing returns, such that increases in the magnitude of review valence have weaker returns on purchase preference and probability, as review valence grows closer to the highest attainable level of review valence possible (i.e., 5/5 stars).

For instance, Bosman, Boshoff, and van Rooyen (2013) found that for every additional star rating, perceived credibility of online reviews decreased by $2.39 \%$. In addition, there is some evidence to suggest that moderately positive reviews, as opposed to extremely positive reviews, tend to be more persuasive (Kupor and Tormala 2018), such that consumers find them more helpful (Kim, Maslowska, and Malthouse 2018), leading to a higher likelihood of purchase (Maslowska, Malthouse, and Bernritter 2017). Ludwig et al. (2013) further found that an 
increase in valence led to a smaller gain than a loss as a result of a decrease in valence (also see Dholakia 2014).

However, because of the intentionally covert nature of the online product review process, it is plausible that many online consumers may be unaware of the extent to which fraudulent review practices are employed in electronic commerce. Despite widespread media (e.g., Manskar 2020; N. Nguyen 2019; V. Nguyen 2019; Picchi 2019) and academic (e.g., Munzel 2016; Ruan, Deng, and Su 2020; Salehan and Kim 2016; Zhang et al. 2016) attention to the proliferation of fake reviews, a recent survey (Sterling 2019) indicated that three-quarters of participants trusted Amazon.com reviews "fully" or "somewhat." Anecdotally, this could help explain a consistent finding in extant research reporting a linear relationship between review positivity and consumer preference (e.g., Chevalier and Mayzlin 2006), despite reported settlements many firms have already made with the FTC because of their deceptive attempts to persuade consumer sentiment via manipulating online reviews (FTC 2016; NPR 2013). Consequently, when deceptive online review practices are not salient in consumers' minds, we would expect greater persuasive effects (i.e., more favorable consumer responses) as product star-ratings become more positive. In contrast, when consumers become aware of these practices, we expect evaluations of a product will be less favorable, especially when product reviews are highly positive. This suggests a pattern of relationships consistent with the following hypotheses:

$\mathrm{H}_{1}$ : The effect of review valence on consumer responses will be moderated by awareness of deceptive online practices, such that as review valence becomes more positive, awareness (unawareness) of deceptive practices will decrease (increase) (a) attitude toward the product, and (b) purchase intentions. 
After becoming aware of deceptive practices employed by e-retailers and manufacturers, it is reasonable to expect that consumers would likely infer some type of bias in the process and the reviews themselves. Advertising tactics such as using a biased source have been linked to higher levels of perceived advertiser manipulative intent, which has been shown to contribute to less-favorable brand evaluations (Kirmani and Zhu 2007). Likewise, one might expect that perceptions of manipulative intent will increase when consumers are aware of deceptive online review practices, thereby negatively impacting their perceptions of the product (consistent with a non-linear effect of review valence) and reducing their purchase intentions. However, when consumers are less aware of these deceptive practices, the level of perceived manipulative intent is expected to be lower, thereby yielding more favorable consumer responses as the valence of the reviews become more positive (consistent with a linear effect of review valence).

This finding is supported by investigations revealing that perceptions of manipulative intent negatively co-vary with consumers' perceptions of ad credibility, such that when consumers perceive a higher level of manipulative intent on the part an advertiser, they are also more likely to perceive a lower level of ad credibility (Cotte, Coulter, and Moore 2005). Additionally, higher levels of perceived manipulative intent have been shown to negatively influence consumers' subsequent evaluations of products, services, and companies (Campbell and Kirmani 2000; Kirmani and Zhu 2007). Because information regarding online deceptive tactics is likely to be incorporated into the consumer's "persuasion knowledge" - helping her/him "cope" with related and subsequent persuasive episodes - manipulative intent seems likely to be the mechanism underlying consumer reaction to deceptive reviews in the online marketplace (Campbell and Kirmani 2000; Friestad and Wright 1994). Hence, we further hypothesize: 
$\mathrm{H}_{2}$ : Perceptions of manipulative intent will mediate the interaction between review valence and awareness of deceptive online review practices on (a) attitude toward the product, and (b) purchase intentions.

\section{EXPLORATORY PILOT STUDY}

Although one might assume that a reasonable number of consumers are already aware of some aspects of online tampering of product reviews, our first task was to conduct an exploratory pilot study to provide a baseline measure of consumers' current awareness of the existence of specific online review practices. As such, participants were recruited from a national sample, utilizing Amazon's Mechanical Turk $(N=197,40.6 \%$ female, age range $=18-70$; median age $=32 ; 76.6 \%$ Caucasian), and were paid $\$ .75$ for their participation in an 8-minute survey (within the range of MTurker compensation reported by Sheehan and Pittman 2016). In terms of geographic location, $40.6 \%$ of participants reported living in the South, $20.8 \%$ in the West, $20.3 \%$ in the Midwest, and $18.3 \%$ in the Northeast.

Participants were first asked about the general trustworthiness of online reviews. Our findings indicated that a majority of online reviews were perceived to be authentic $(M=67.2 \%$; $S D=16.6 ;$ median $=70 \%)$ and accurate $(M=65.5 \% ; S D=17.7 ;$ median $=70 \%)$. This finding is consistent with a Pew Research Center report which noted that two-thirds of online shoppers who read product reviews on a regular basis perceived them to be "generally accurate" (Smith and Anderson, 2014). Interestingly, the Pew report also noted that a substantial minority of adults they surveyed admitted that it, nonetheless, can be difficult to determine the truthfulness of online reviews.

Next, participants were asked to give a binary ("yes" or "no") answer regarding their general awareness of specific online review practices. Here, our results indicated that 
approximately half (52.8\%) of the participants were unaware of potentially deceptive practices. Specifically, $43.7 \%$ of participants indicated that they were not aware that online retailers sometimes offer free products to individuals who post online reviews on their sites. Further, $74.6 \%$ of participants indicated that they were not aware of online retailers' practices of funneling reviews from manufacturers' websites.

Finally, we asked participants to rate these and two other specific online review practices in terms of their perceived ethicality $(1=$ "very unethical business practice," 4 = "neither ethical nor unethical business practice," $7=$ "very ethical business practice"). Comparisons to the neutral scale midpoint of 4.0 indicated that participants rated each example given as unethical (see Table 1).

[Insert Table 1 about here]

Together, these findings offer evidence that a significant number of consumers may be generally trusting of online reviews, even when further scrutiny may be warranted. Consistent with research reports noted earlier, a substantial portion of participants in our exploratory study were largely unaware of some potentially deceptive review practices currently in use - practices that once explained to them, were subsequently evaluated as being unethical. With these observations as a starting point, we sought to empirically investigate the interactive effect of review valence and consumer awareness of online review practices on product evaluations, as well as to provide an explanation of the hypothesized underlying cause of these responses (i.e., a potential mediating role played by perceptions of manipulative intent).

\section{STUDY 1}

Study 1 was designed with two goals in mind: (1) to examine the extent to which participants' awareness of deceptive online review practices influences their evaluative 
judgments of products associated with 4.5, 4.7, and 4.9 star ratings $\left(\mathrm{H}_{1}\right)$, and; (2) to determine whether consumer perceptions of e-retailers' manipulative intent mediate these effects $\left(\mathrm{H}_{2}\right)$. Regarding our first goal, we expected that participants' awareness of deceptive online review practices would moderate star-ratings effects, with exposure to a news article reporting on these practices (vs. exposure to an article on an unrelated topic) reducing their assessments of the reviewed product. Regarding the second goal, we expected perceived manipulative intent would mediate the interactive effects of review valence and awareness of deceptive online ratings practices on participants' product attitudes and purchase intentions.

\section{Participants, Study Design, and Measures}

Participants were recruited from Amazon's Mechanical Turk $(N=355 ; 51.5 \%$ female; age range $=18-78 ;$ median age $=33 ; 75.8 \%$ Caucasian; geographic location: South $=38.6 \%$, Northeast $=22.3 \%$, West $=20.3 \%$, Midwest $=18.9 \%$, and were paid $\$ .75$ for their participation in an 8-minute study. The study employed a 3 (Valence: Average rating of 4.9 stars vs. 4.7 stars vs. 4.5 stars) x 2 (Awareness of deceptive online review practices: Aware vs. Unaware), between-subjects design. Participants in the "aware" condition were asked to read an article that purportedly appeared in a well-known business publication describing deceptive online review practices, whereas participants in the "unaware" condition read an article on autonomous cars. The commentary, titled "Can Online Reviews be Trusted?," was designed to inform study participants that several types of online reviews may be inaccurate and/or biased. Participants in both conditions were then exposed to one of the three stimuli, varying only in the valence of overall consumer ratings of the product (i.e., 4.5 vs. 4.7 vs. 4.9 out of 5 stars). Participants were then told they would be viewing a screenshot of an electric toothbrush from an online retailer's website. The screenshot included a promotional product description, the listed price (determined 
using a pretest ${ }^{2}$ ), a breakdown of customer ratings, and an overall (summary) customer rating value (see Appendix A).

After reviewing the screenshot, participants indicated their likelihood of purchasing this product the next time they were on the market for an electric toothbrush, using a three-item scale (adapted from Ajzen and Fishbein 1980; e.g., 1 = "unlikely" vs. 7 = "likely"; $\alpha=.95$ ), and their attitude toward the product, using a seven-item scale (adapted from Peracchio and Meyers-Levy 1997; e.g., 1 = "mediocre” vs. 7 = "exceptional;" $\alpha=.94)$.

Following the collection of dependent measures, participants completed a six-item manipulative intent scale (adapted from Campbell 1995; e.g., "The reviews try to manipulate potential consumers in ways that I don't like," 1 = "strongly disagree" vs. 7 = "strongly agree;" $\alpha$ $=.92$; see Table 2 for descriptive statistics and correlation matrix). Finally, participants completed an attention-check question to assess whether they were paying attention and following instructions as directed, and a manipulation-check question corresponding to the numerical star-valence of the overall customer ratings contained in the experimental stimuli (see Appendix B for all scale items, attention-check, and manipulation-check questions).

[Insert Table 2 about here]

\section{Results}

\section{Attention- and Manipulation-Checks}

In an assessment of data collections using MTurk samples, Thomas and Clifford (2017, 191) noted that excluding survey responses from inattentive participants can "effectively reduce

\footnotetext{
${ }^{2}$ Using participants from Amazon's Mechanical Turk $(N=100 ; 43 \%$ female; median age $=29 ; 69 \%$ Caucasian $)$, who were paid $\$ .50$ for taking a 3-minute survey, we conducted a price pretest. Participants were shown a screenshot for an electric toothbrush and its specifications (same as in Appendix A, except without review or price information), and answered two questions: (1) How much do you think this electric toothbrush is worth?; and, (2) How much do you think this electric toothbrush costs? The mean price for Q1 was \$32.56, and \$39.91 for Q2. Hence, a price of $\$ 34.99$ was determined to be realistic, and was used in our subsequent empirical investigation.
} 
statistical noise without introducing any significant systematic sampling bias" (see, also:

Oppenheimer, Meyvis, and Davidenko 2009). Consistent with these and similar processes reported in the literature (Berinsky, Margolis, and Sances 2014; Goodman, Cryder, and Cheema 2013; Kareklas, Muehling and Weber 2015), we elected to exclude from subsequent analyses, sixty-five participants who failed either the attention- or manipulation-check measures, leaving us with a final sample of 290 participants.

Hypothesis Tests

ANOVA tests of $\mathrm{H}_{1 \mathrm{a}}$ and $\mathrm{H}_{1 \mathrm{~b}}$ (i.e., the effect of review valence on consumer responses will be moderated by awareness of deceptive online practices) revealed a significant interaction between valence and awareness on attitude $(F(2,284)=2.68, p=.07)$ and purchase intentions ${ }^{3}$ $F(2,284)=3.22, p<.05$; see Table 3$)$. Within the 4.9-star valence condition, participants who read the deceptive online ratings review commentary ("aware" group) reported significantly lower attitudes and purchase intentions $(p<.05)$, compared to those who read the unrelated commentary ("unaware" group). Within the 4.5-star and 4.7-star valence conditions, there were no significant differences in attitude and purchase intentions between the aware and unaware groups (see Figure 1).

\section{[Insert Table 3 and Figure 1 about here]}

As a follow-up to the observed pattern of relationships, we employed PROCESS Model 8 (Hayes 2018) to examine whether the effect of the valence $x$ awareness interaction on attitudes and purchase intentions may be mediated by manipulative intent (95\% confidence interval with

\footnotetext{
${ }^{3}$ Although not hypothesized, we also examined the valence $\mathrm{x}$ awareness interaction on manipulative intent. Results showed that the valence $\mathrm{x}$ awareness interaction was a significant predictor of manipulative intent $(F(2,284)=7.47$, $p<.001$; see Table 3). Among those in the aware condition, the review valence condition of 4.9 led to significantly higher perceptions of manipulative intent than the 4.7 and 4.5 conditions, while there was no significant effect of valence on manipulative intent among participants in the unaware condition (see Figure 1 for a graph).
} 
1,000 bootstrap samples) (see Figure 2). In support of $\mathrm{H}_{2 \mathrm{a}}$ and $\mathrm{H}_{2 \mathrm{~b}}$, results indicated that the conditional indirect effect of valence through manipulative intent was significant $(B=-.31, S E=$ $.09,95 \%$ CI: -.4963 to -.1479$)$. Specifically, in the aware condition, review valence had both a significant direct and indirect effect on attitude (direct: $B=.23, S E=.09,95 \% C I: .0550$ to .4005 ; indirect: $B=-.23, S E=.09,95 \% C I:-.3849$ to -.0922$)$, while only the direct effect was significant for the unaware condition (indirect: $B=.08, S E=.05,95 \% C I$ : -.0061 to .1789 ; direct: $B=.23, S E=.29,95 \% C I: .0636$ to .4008$)$. A relatively similar pattern of effects was observed when purchase intention was used as the dependent variable $(B=-.41, S E=.12,95 \%$ CI: -.6660 to -.1946). In the aware condition, the indirect effect of valence on purchase intentions through manipulative intent was significant $(B=-.30, S E=.10,95 \% C I:-.5141$ to -.1254$)$, while the direct effect was not significant $(B=.23, S E=.13,95 \% C I:-.0341$ to .4913$)$. In the unaware condition, the direct effect of valence on purchase intentions was significant $(B=.34$, $S E=.13,95 \% C I: .0872$ to .5999$)$, while the indirect effect through manipulative intent was not significant $(B=.11, S E=.06,95 \% C I:-.0129$ to .2300$)$. These findings suggest that review valence is positively related to attitude and purchase intentions when participants are unaware of deceptive online ratings review practices, but when they are aware of such practices, product evaluations are less favorable, due to perceptions of manipulative intent.

[Insert Figure 2 about here]

\section{STUDY 2}

As reported earlier, some evidence in the literature suggests that a perfect 5-star rating may not be more desirable than a highly positive, but more plausible rating of 4.5-stars, because it may be viewed with greater skepticism (see, e.g., Collinger and Malthouse 2015). Such a notion suggests a different pattern of relationships than what we had observed previously for 
products having 4.9-star ratings in the "unaware" condition in Study 1. To address this issue, we introduced a perfect (5.0/5.0-star) review condition in Study 2 and compared it to a 4.5/5.0-star review (see Appendix $\mathrm{C}$ for stimuli). We expected that when the average of all ratings was a perfect 5.0, participants' assessment of the product would be no more favorable than a product featuring an average 4.5 rating, and therefore, would alter the pattern of relationships originally observed in Study 1. This expectation is based upon the assumption that exposure to perfectscore ratings may raise additional doubt in the minds of consumers, due to perceptions that a 5.0 rating is "too good to be true" (Collinger and Malthouse 2015, 9). In Study 2, we also employed an augmented measure of manipulative intent that included additional assessments of the perceived trustworthiness and credibility of the online reviews, adapted from Flanagin and Metzger (2000). ${ }^{4}$

Additionally, in our previous study we exposed participants to the study stimuli (i.e., online product reviews) immediately after having them read an article related or unrelated to deceptive online review practices. This may have created some unforeseen demand effects. For example, reading the news article on online reviews and then immediately being exposed to a product rating site may lead to hypothesis guessing (Mummolo and Peterson 2019). In addition, it is uncommon for consumers to evaluate a product in a real-world setting, immediately after learning about manipulative review practices. To avoid such demand effects, researchers often use distractor or filler tasks (e.g., Mitra and Lynch 1995; Posavac, Herzenstein, and Sanbonmatsu 2003; Venkatraman et al. 2015). Similarly, in Study 2, we separated the reading

\footnotetext{
${ }^{4}$ The augmented measure was designed to tap into additional underlying reasons for participants' perceptions of manipulative intent, consistent with the ad credibility literature discussed in an earlier section of this paper (Cotte, Coulter, and Moore 2005). The 12-item scale, utilizing measures of star-rating credibility and manipulative intent, was found to be internally consistent $(\alpha=.97)$. Factor analysis results (with varimax rotation) yielded a one-factor solution.
} 
task and stimulus exposure by inserting a distractor task which focused on an entirely unrelated activity. The distractor task employed asked participants to complete a common scientific literacy test (i.e., True/False questions about radioactivity, lasers, orbits of the moon and earth, etc.; adapted from Kahan et al. 2012). Participation in this activity was designed to serve as a mental buffer and provided a time delay prior to participants returning to the study-relevant tasks of reviewing the experimental stimuli and responding to the study measures.

\section{Participants, Study Design, and Measures}

Participants were recruited from Amazon's Mechanical Turk ${ }^{5}(N=362,43.9 \%$ female, age range $=19-74 ;$ median age $=34 ; 79.6 \%$ Caucasian; geographic location: South $=38.9 \%$, West $=23.6 \%$, Midwest $=18.8 \%$, Northeast $=18.8 \%$, and were paid $\$ 1$ for their participation in a 10-minute study. The study employed a 2 (Valence: Average rating of 5.0 stars vs. 4.5 stars) x 2 (Awareness of deceptive online reviews practices: Aware vs. Unaware), between-subjects design. Once again, participants completed items measuring purchase intentions $(\alpha=.95)$, attitude toward the product, $(\alpha=.95)$, and manipulative intent $(\alpha=.97)$. Additionally, participants answered an attention-check question (similar to the one employed in Study 1), and three manipulation-check questions to ensure the experimental treatments were interpreted as anticipated (see Appendix B for a list of these questions).

\section{Results}

Attention- and Manipulation-Checks

Forty-eight participants failed either the attention-check or one of the three manipulationchecks. Responses from these participants were therefore excluded from all subsequent analyses, leaving a final sample of 314.

\footnotetext{
${ }^{5}$ Study 1 participants were excluded from participating in Study 2.
} 


\section{Hypotheses Tests}

ANOVA tests focusing on the interactive effects of review valence and awareness on consumer responses yielded significant findings, consistent with $\mathrm{H}_{1 \mathrm{a}}$ and $\mathrm{H}_{1 \mathrm{~b}}$ (see Table 4$)^{6}$. Participants who read the unrelated commentary reported no greater product attitude $(p=.32)$ or purchase intentions $(p=.45)$ when exposed to the 5-star rating stimulus, as compared to the 4.5star rating stimulus. However, reading the commentary focusing on deceptive online reviews significantly reduced participants' evaluations of the product in the perfect (i.e., 5-star) condition. Attitudes and purchase intentions were significantly lower when the product was featured with a perfect 5-star review, as compared to 4.5-star review (see Figure 3).

To elaborate on this interaction further, we conducted follow-up analyses to test the effect of awareness of potentially deceptive online review practices within each condition of valence. As expected, we found that among participants who were exposed to the stimulus featuring 4.5star ratings, awareness had no effect on attitude $(p=.45)$ or purchase intentions $(p=.55)$. However, awareness did have a significant (detrimental) effect on both attitude $(p<.001)$ and purchase intentions $(p<.001)$ within the 5.0-star rating condition, suggesting that attitude and purchase intentions were lower after reading an article focusing on deceptive online reviews (vs. an article focusing on an unrelated topic). ${ }^{7}$ These findings suggest that, although awareness (vs. unawareness) of deceptive online practices may not significantly alter participants' product

\footnotetext{
${ }^{6}$ We again investigated the valence $\mathrm{x}$ awareness interaction on manipulative intent, and found it to be a significant predictor of manipulative intent $(F(1,310)=4.03, p<.05$; see Table 4). Participants perceived manipulative intent in both conditions, but inferences were greater in the aware condition (vs. unaware condition). Follow-up tests suggest there were no difference in manipulative intent between the aware and unaware groups within the 4.5-star rating condition, while those in the aware group (compared to the unaware group) reported significantly greater perceptions of manipulative intent within the 5.0-star rating condition (see Figure 3 for a graph).

${ }^{7}$ To assess whether older vs. younger individuals would respond differently to the online reviews (perhaps because of differences in perceived trustworthiness; Smith and Anderson 2019), we reran these analyses with age as a covariate. No differences in results were observed.
} 
evaluations of a 4.5-star rated product, it may significantly lower their evaluations of a 5.0-star rated product (see Table 4).

[Insert Table 4, Figure 3, and Figure 4 about here]

To again test for a mediating role of manipulative intent (i.e., $\mathrm{H}_{2 \mathrm{a}}$ and $\mathrm{H}_{2 \mathrm{~b}}$ ), we employed PROCESS Model 8 (Hayes 2018). A 95\% confidence interval (with 1,000 bootstrap samples) was used to test the indirect effect of the interaction between valence and awareness on each of the dependent variables (see Figure 4). In support of our hypotheses, the overall moderated mediation model was significant $(B=-.44, S E=.22,95 \% C I:-.8822$ to -.0146$)$ on attitude, revealing that the indirect effect of valence on attitude through manipulative intent was stronger in the aware condition $(B=-1.01, \mathrm{SE}=.17,95 \% C I:-1.3493$ to -.6578$)$ than in the unaware condition $(B=-.56, \mathrm{SE}=.16,95 \% C I:-.8756$ to -.2639$)$. In addition, the conditional direct effect of valence on attitude remained significant at both levels of awareness, since the $95 \%$ confidence interval did not include zero, suggesting partial mediation of manipulative intent. Similarly, results indicated that the overall mediated moderation model was significant $(B=-.51, S E=.26$, 95\% CI: -1.0107 to -.0161$)$ when purchase intention was the dependent variable, with the indirect effect of valence on purchase intentions through manipulative intent stronger in the aware condition $(B=-1.14, S E=.20,95 \% C I:-1.5456$ to -.7528$)$ than in the unaware condition $(B=-.63, S E=.17,95 \% C I:-.9826$ to -.2970$)$. Finally, the test of a conditional direct effect of valence on purchase intentions remained significant for the unrelated commentary (i.e., unaware group), but was not significant for the aware group - suggesting that manipulative intent partially-mediated the effect of valence on purchase intentions for participants who read the unrelated commentary, but fully-mediated this effect when participants were exposed to an article focusing on deceptive online reviews. 


\section{GENERAL DISCUSSION}

Using the findings of our exploratory pilot study as a starting point, Studies 1 and 2 were designed to contribute to the literature evaluating consumers' responses to favorable online reviews, especially when e-retailers' potentially deceptive review practices are made salient. From these studies, we observed that individuals generally did not tend to perceive high levels of manipulative intent on the part of e-retailers when they were exposed to positive reviews, unless they were aware of fraudulent practices in the online marketplace. However, when they were aware of the potentially deceptive review practices some e-retailers employ, less favorable (and, perhaps, more realistic) attitudes and decreased purchase intentions towards products featured on the e-retailer's website tended to ensue. Our results consistently found that once consumers were exposed to the fact that online ratings may not be trusted, they were more likely to perceive eretailers as attempting to unfairly manipulate their product-related assessments. Importantly, such perceptions of manipulative intent were empirically shown to result in less favorable evaluations of the product.

While the above-mentioned pattern of findings may generally be expected, we found that after learning about or being reminded of deceptive online review practices, individuals in our studies reacted least favorably to reviews featuring highly positive (4.9/5 stars) or perfect (5/5 stars) reviews. Interestingly, awareness of manipulated online review practices had very little differential impact on participants' evaluations of products that were associated with what would appear to be very positive ( $4.5 / 5$ and $4.7 / 5$ stars) ratings. Such a pattern of results illustrates that even skeptical consumers can (and do) differentiate nuanced differences across various levels of review valence. Our findings are consistent with research conducted by Northwestern University in collaboration with PowerReviews, which found that purchase intentions were most favorable 
for reviews averaging between $4.2 / 5$ and $4.5 / 5$ stars, as opposed to perfect 5/5-star reviews (Collinger and Malthouse 2015). Our Study 2 finding that a perfect 5/5 rating yielded no more favorable product attitudes and purchase intentions than a $4.5 / 5$ rating when participants were unaware of manipulated online review practices appears to further support the notion of a "ceiling effect" (Maslowska, Malthouse and Bernritter 2016), suggesting that perfect ratings may sometimes not generate the most favorable consumer responses. In a practical sense, our findings serve as further evidence of the limited benefits for e-retailers manicuring or unfairly manipulating their online reviews to extremes - especially in situations where these strategies are made salient to consumers. As media coverage of potentially deceptive online review practices and concomitant prosecutions against perpetrators grow, consumers are likely to become increasingly aware of such practices, and consequently, even more vigilant towards online review star-ratings - responding in a manner similar to what we observed in our studies.

The present work contributes theoretically to emerging research on potentially deceptive online activity by e-retailers (e.g., Hajli 2018), as well as extant research in the area of deceptive advertising in general (e.g., Preston 2002; Xie, Madrigal, and Boush 2015). Past research has shown that when deception is detected by consumers, diminished attitudes and intentions toward the respective firm, brand, product and/or service are expected (Gardner 1975). In an e-retailing context, our work likewise suggests that consumers may exhibit reduced attitudes and purchase intentions toward products featured on e-retailers' websites when they suspect the reviews may be inaccurate or fraudulent. The findings of Studies 1 and 2 indicate that when potential manipulation is not detected, positive reviews generally serve as a heuristic for product quality and are likely to persuasively influence preferences. However, our findings also suggest that $4.5 / 5$ and $4.7 / 5$ star ratings are not likely to prompt any more perceived manipulative intent when 
consumers are aware (as opposed to when they are not aware) of the prevalence of deceptive online review practices in the marketplace. In addition, perfect or near-perfect product ratings appear to serve as a natural warning flag for consumers, with negative perceptions of manipulative intent further exacerbating the situation when consumers are aware of potentially deceptive online practices. This pattern of effects is likely to continue as more e-retailers face prosecution for their fraudulent practices pertaining to manipulating online reviews posted on their sites. News coverage of such prosecutions both domestically and abroad will likely lead to increasing numbers of consumers becoming aware of deceptive online review practices. As previously noted, the UK has fairly strong consumer protections in place against unfair trading. According to The UK Rules (2020), any e-retailers who are found to "distort" online reviews posted on their sites would be in violation of the Consumer Protection from Unfair Trading Regulations rules and may face prosecution by the Office of Fair Trading for breaching of the Unfair Trading Regulations.

Interestingly, extant research finds that ads containing disclosures (a practice that is common in affiliate marketing where affiliates are expected to disclose they are being paid by merchants they recommend), are sometimes perceived as less helpful (Kim, Maslowska, and Tamaddoni 2019), leading to increased inferences of manipulative intent (Thomas, Fowler, and Grimm 2013), and to more negative perceptions of both the product and the advertisement (Andrews, Burton, and Netemeyer 2000). Therefore, rather than providing confidence in the veracity of the posted reviews, disclosures in the online marketplace may actually increase consumer skepticism - especially in cases where the reviews are exceedingly positive (i.e., 5/5 stars). 
As such, the present work joins a fast growing literature revealing a potentially prominent role for inferences of manipulative intent in consumer decision-making in the online realm (e.g., Choi et al. 2018; Ma and Lee 2014; Thomas, Fowler, and Grimm 2013; Weber, Kareklas, and Muehling 2019; Zhang, Ko, and Carpenter 2016). Indeed, while eWOM has democratized consumer behavior through the dissemination of user-generated content aiding decision-making, it has also facilitated novel methods for manipulation among e-retailers trying to stimulate business through methods many consumers may not find ethical. Such a finding underscores how challenging the task may be for legitimate e-retailers to convince consumers that their posted reviews can be trusted. In other words, unfair practices related to online review manipulation has the potential to greatly impact e-retailing in general, including e-retailers who do not engage in any forms of review manipulation. Such an outcome would be unfortunate for the industry as a whole, as well as for consumers who have grown to rely on online product reviews for their decision making.

\section{Recommendations}

Based on our work in this area, we believe that online retailers who do not engage in deceptive online review practices must take the necessary steps to distinguish themselves from eretailers who do, for the same reason the American Association of Advertising Agencies, the American Advertising Federation, and the American Academy of Advertising "waged war" on deceptive advertising throughout the $20^{\text {th }}$ century (Carson, Wokutch, and Cox 1985). Specifically, e-retailers should take greater strides in verifying and disclosing the authenticity of reviews on their site(s) - but, in a manner that does not further enhance consumers' skepticism and distrust of their actions. Like the eradication of "Payola" schemes on radio stations in the 1950's and the crackdown of deceptive television advertising in the 1980's, such a change would 
send a positive signal to consumers, suggesting that e-retailers are taking the necessary steps to authenticate the content appearing on their websites.

Online sites offering verifications of posted reviews appear to be a potential step forward in ensuring online reviews are at a minimum originating from a consumer who purchased the product or service from the e-retailer. Initial research suggests that verification - through visual cues, or confirming a purchase was actually made - may be a positive step in regulating deceptive online review practices (Malthouse and Askalidis 2015). While verified review effects are not universally strong (cf. Kim, Maslowska, and Malthouse 2018), they offer a potential first step in building consumer trust in an e-retailing context increasingly fraught with consumer skepticism resulting from strategies aimed at increasing the number of positive reviews at the expense of objectivity. Furthermore, noting which of the reviews that appear on e-retailers' sites are associated with verified purchases and which are not may help honest retailers distinguish themselves from e-retailers engaging in deceptive practices.

As an example, the Better Business Bureau (BBB) has recently implemented a program called "Customer-Verified Reviews," which requires consumers to certify they have not been offered any incentive or payment from the business that is the focus of their evaluation (Better Business Bureau 2020). The reviews are vetted by the BBB, and in some cases, additional substantiation of interactions between the company and the reviewer is required, before they are published online. In its interpretation of recently settled cases, it appears that the Federal Trade Commission is also taking a tougher stance on fraudulent online reviews, noting that it will take enforcement action against firms and/or individuals who post deceptive or inaccurate information online (Cottrell and Cook 2019; see also Fair 2019 for an example of the FTC's interpretation of BBB-verified reviews). 
In keeping with this notion, several prominent e-retailers such as Amazon.com have begun identifying which of the reviews appearing on their sites are posted by reviewers whose purchases can be verified. However, most of these sites still feature larger numbers of unverified reviews, which we believe may continue to create consumer confusion, and might even lead to reduced trust and increased perceptions of manipulative intent moving forward. We posit that these practices have the potential to damage the reputations of e-retailers, and based on our present findings, we recommend that at a minimum, customers should be given the option to sort the reviews by verified and unverified purchases, so they can more easily focus their attention on organic reviews that have a greater likelihood to be legitimate and unbiased. While not all reviews from unverified purchases are misleading, overall, reviews from verified purchases may draw a slightly more accurate picture of customer experience with the product subject to the review and be free of financial entanglements.

It should also be noted that Amazon.com recently updated the algorithm ("machine learned model") it uses for computing the average star ratings of products on its website to take into consideration factors such as, "the age of a review, helpfulness votes by customers, and whether the reviews are from verified purchases" (quoted text appears when users hover over the average star ratings of products on Amazon.com). However, the exact algorithm Amazon uses has not been publicly disclosed, and as the company notes, is not based on "a raw data average." The lack of transparency regarding how this e-retailer computes and reports the average ratings from reviews appearing on their website is troubling, especially since Amazon.com reportedly accounts for $\$ 282$ billion dollars and $47 \%$ of online retail sales in the U.S. (Stych 2019).

Furthermore, boosting the average star ratings of products when positive reviews are voted to be helpful (and negative reviews are voted to be unhelpful), provides additional avenues 
for fraudulent online review practices. As such, firms may be tempted to task their employees with specifically "voting up" positive online reviews of their products and "voting down" negative reviews in hopes of boosting sales. This is exactly what skin care brand Sunday Riley was accused of doing on its Sephora's website over a period of approximately two years (CNN 2019). According to the FTC, the CEO of the company was found to be complicit, as emails emerged in which she had instructed her employees to "write glowing reviews and bury negative ones," and offering detailed instructions on how to avoid detection (CNN 2019). A portion of one email read, "If you see a negative review -- DISLIKE it... After enough dislikes, it is removed. This directly translates to sales!!” (CNN 2019).

\section{Future Research Directions}

Past research documents that about $70 \%$ of all consumers perceive advertising claims as untruthful and often exaggerated (Calfee and Ringold 1994). Hence, research focusing on eWOM in a promotional context could examine how individual differences in advertising skepticism (Obermiller and Spangenberg 1998) impact consumer reactions to e-retailers, especially those who are found to engage in potentially deceptive online review practices. This would be an important extension to our work, as research finds that even truthful advertising is often questioned by consumers who believe that ad claims may sound "too good to be true" (Koslow 2000). Additionally, with increasing news coverage of deceptive review practices, as discussed above, it is reasonable to expect that increasing numbers of consumers will exhibit advertising skepticism toward companies touting their positive reviews, even among consumers who do not typically rate high on advertising skepticism. Similarly, it is plausible that consumers who do score high on the individual difference characteristic of advertising skepticism would also likely perceive that e-retailers may have engaged in deceptive review practices when 
encountering products with a large volume of exceedingly positive reviews, even when they have not. Furthermore, future research may wish to identify consumer/participant groups prior to running their main studies and assign them based on their existing knowledge of these deceptive practices, thereby reducing the need to expose them to experimenter-generated awareness manipulations.

Additionally, in Study 2, we used a distractor task (i.e., a nine-item true/false scientific literacy test adapted from Kahan et al. 2012), which may have inadvertently caused some participants to experience cognitive resource depletion, as the task required participants to do additional cognitive processing that otherwise would not have occurred. Although we have no data to support this supposition, future research wishing to replicate and extend our findings may want to consider including a measure of resource depletion to account for any potential unexpected outcome due to the use of a filler task, like the one employed in our study.

We also recognize that a number of other factors (not specifically examined in the current set of studies) could influence the pattern of effects reported here and are worthy of further empirical examination. For example, rating variance (the distribution of high and low starratings; Sun 2012), rating volume (the quantity/number of reported reviews; Yang, Sarathy and Lee 2016), as well as a variety of consumer traits and dispositions (see, e.g., Lee and Ma 2012; Maslowska et al. 2019; Lin and Xu 2017), may independently or in combination with one another, influence consumers' online product evaluations. A more comprehensive examination of these and other factors would certainly contribute to the online review literature.

Finally, we further believe our work contributes to a burgeoning research stream under the umbrella of "transformative service research," which seeks to enhance the welfare of both service entities and consumer welfare through marketing research (Anderson et al. 2013). 
Although deceptive online review practices have considerable potential to adversely impact consumer trust toward e-retailers and manufacturers found to engage in these practices, they may also cause consumers to distrust legitimate reviews, as well as e-retailers and manufacturers who do not engage in review manipulation. As such, we hope the present research will help spur future empirical work that considers how increased distrust of eWOM may affect the interplay between consumers and service entities in e-retailing, persuasion, and the marketing of services more generally. 


\section{REFERENCES}

Ajzen, Icek, and Martin Fishbein. 1980. Understanding Attitudes and Predicting Social Behavior. Englewood Cliffs, N.J.: Prentice-Hall.

Anderson, Eric T., and Duncan I. Simester. 2014. "Reviews without a Purchase: Low Ratings, Loyal Customers, and Deception.” Journal of Marketing Research 51 (3): 249-269.

Anderson, Laurel, Amy L. Ostrom, Canan Corus, Raymond P. Fisk, Andrew S. Gallan, Mario Giraldo, Martin Mende, Mark Mulder, Steven W. Rayburn, Mark S. Rosenbaum, Kunio Shirahada, and Jerome D. Williams. 2013. "Transformative Service Research: An Agenda for the Future." Journal of Business Research, 66 (8): 1203-1210.

Andrews, J. Craig, Scot Burton, and Richard G. Netemeyer. 2000. “Are Some Comparative Nutrition Claims Misleading? The Role of Nutrition Knowledge, Ad Claim Type and Disclosure Conditions.” Journal of Advertising 29 (3): 29-42.

Baker, Phil. 2017. "Deception on the Internet Is Nothing New, but You're Right, It Is Getting Worse.” Accessed on September 25, 2019. https://www.vox.com/2017/10/9/16448962/fakenews-truth-deception-internet-fraud-review-support-sites

Beaton, Caroline. 2018. “Why You Can’t Really Trust Negative Online Reviews - The New York Times.” Accessed on September 25, 2019.

https://www.nytimes.com/2018/06/13/smarter-living/trust-negative-product-reviews.html

Belanche, Daniel, Carlos Flavián, and Alfredo Pérez-Rueda. 2020. "Consumer Empowerment in Interactive Advertising and eWOM Consequences: The PITRE Model." Journal of Marketing Communications 26 (1): 1-20. 
Berinsky, Adam J., Michele F. Margolis, and Michael W. Sances. 2014. "Separating the Shirkers from the Workers? Making Sure Respondents Pay Attention on Self-Administered Surveys." American Journal of Political Science 58 (3): 739-753.

Better Business Bureau. 2020. “Customer-Verified Reviews.” Accessed on January 20, 2019. https://www.bbb.org/chicago/programs-services/customer-reviews/

Blal, Inès, and Michael C. Sturman. 2014. “The Differential Effects of the Quality and Quantity of Online Reviews on Hotel Room Sales.” Cornell Hospitality Quarterly 55 (4): 365-375.

Bosman, Dirk J., Christo Boshoff, and Gert-Jan Van Rooyen. 2013. "The Review Credibility of Electronic Word-of-Mouth Communication on E-Commerce Platforms." Management Dynamics: Journal of the Southern African Institute for Management Scientists 22 (3): 2944.

Buttle, Francis A. 1998. "Word of Mouth: Understanding and Managing Referral Marketing." Journal of Strategic Marketing 6 (3): 241-254.

Calfee, John E., and Debra Jones Ringold. 1994. “The 70\% Majority: Enduring Consumer Beliefs about Advertising." Journal of Public Policy \& Marketing 13 (2): 228-238.

Campbell, Margaret C. 1995. "When Attention-Getting Advertising Tactics Elicit Consumer Inferences of Manipulative Intent: The Importance of Balancing Benefits and Investments.” Journal of Consumer Psychology 4 (3): 225-254.

Campbell, Margaret C., and Amna Kirmani. 2000. “Consumers' Use of Persuasion Knowledge: The Effects of Accessibility and Cognitive Capacity on Perceptions of an Influence Agent." Journal of Consumer Research 27 (1): 69-83.

Carson, Thomas L., Richard E. Wokutch, and James E. Cox. 1985. “An Ethical Analysis of Deception in Advertising." Journal of Business Ethics 4 (2): 93-104. 
Cheung, Man Yee, Chuan Luo, Choon Ling Sia, and Huaping Chen. 2009. "Credibility of Electronic Word-of-Mouth: Informational and Normative Determinants of on-Line Consumer Recommendations." International Journal of Electronic Commerce 13 (4): 9-38. Cheung, Christy MK, and Dimple R. Thadani. 2012. "The Impact of Electronic Word-of-Mouth Communication: A Literature Analysis and Integrative Model.” Decision Support Systems 54 (1): 461-470.

Chevalier, Judith A., and Dina Mayzlin. 2006. "The Effect of Word of Mouth on Sales: Online Book Reviews." Journal of Marketing Research 43 (3): 345-354.

Choi, Dongwon, Hyejin Bang, Bartosz W. Wojdynski, Yen-I. Lee, and Kate M. Keib. 2018. "How Brand Disclosure Timing and Brand Prominence Influence Consumer's Intention to Share Branded Entertainment Content." Journal of Interactive Marketing 42: 18-31.

CNN. 2019. "Skin Care Brand Sunday Riley Wrote Fake Sephora Reviews for Almost Two Years, FTC says.” Accessed on February 6, 2020: https://www.cnn.com/2019/10/22/us/sunday-riley-fake-reviews-trnd/index.html

Collinger, Tom, and Edward C. Malthouse. 2015. "From Reviews to Revenue: How Star Ratings and Review Content Influence Purchase.” Power Reviews, Northwestern University, 1, 1-22. Cotte, June, Robin A. Coulter, and Melissa Moore. 2005. "Enhancing or Disrupting Guilt: The Role of Ad Credibility and Perceived Manipulative Intent.” Journal of Business Research 58 (3): $361-368$.

Cottrell, Andrea, and Hudson Cook. 2019. "Online Reviews Become a Focus of the FTC.” JDSupra. Accessed on January 26, 2020: https://www.ftc.gov/news-events/blogs/businessblog/2019/04/its-unwise-incentivize-positive-skewed-reviews 
Dholakia, Pratik. 2014. “Are Excessively Positive Customer Reviews Hurting Your Conversion Rates? [Study].” Accessed on January 22, 2020. https://unbounce.com/conversion-rateoptimization/customer-reviews-conversion-rates/

Edelman, Benjamin, and Wesley Brandi. 2015. "Risk, Information, and Incentives in Online Affiliate Marketing.” Journal of Marketing Research 52 (1): 1-12.

Fair, Lesley. 2019. "It's Unwise to Incentivize Positive Skewed Reviews.” Federal Trade Commission. Accessed on January 26, 2020: https://www.ftc.gov/newsevents/blogs/business-blog/2019/04/its-unwise-incentivize-positive-skewed-reviews

Fan, Yi-Wen, Yi-Feng Miao, Yu-Hsien Fang, and Ruei-Yun Lin. 2013. "Establishing the Adoption of Electronic Word-of-Mouth through Consumers’ Perceived Credibility.” International Business Research 6 (3): 58-65.

Federal Trade Commission. 2016. "Warner Bros. Settles FTC Charges It Failed to Adequately Disclose It Paid Online Influencers to Post Gameplay Videos.” Accessed on September 25, 2019. https://www.ftc.gov/news-events/press-releases/2016/07/warner-bros-settles-ftccharges-it-failed-adequately-disclose-it

Federal Trade Commission. 2019. "FTC Brings First Case Challenging Fake Paid Reviews on an Independent Retail Website.” Accessed on September 25, 2019. https://www.ftc.gov/newsevents/press-releases/2019/02/ftc-brings-first-case-challenging-fake-paid-reviewsindependent

Flanagin, Andrew J., and Miriam J. Metzger. 2000. "Perceptions of Internet Information Credibility.” Journalism \& Mass Communication Quarterly 77 (3): 515-540. 
Flanagin, Andrew J., and Miriam J. Metzger. 2013. "Trusting Expert-versus User-Generated Ratings Online: The Role of Information Volume, Valence, and Consumer Characteristics." Computers in Human Behavior 29 (4): 1626-1634.

Floh, Arne, Monika Koller, and Alexander Zauner. 2013. “Taking a Deeper Look at Online Reviews: The Asymmetric Effect of Valence Intensity on Shopping Behaviour.” Journal of Marketing Management 29 (5-6): 646-670.

Floyd, Kristopher, Ryan Freling, Saad Alhoqail, Hyun Young Cho, and Traci Freling. 2014. “How Online Product Reviews Affect Retail Sales: A Meta-Analysis.” Journal of Retailing 90 (2): 217-232.

Friestad, Marian, and Peter Wright. 1994. “The Persuasion Knowledge Model: How People Cope with Persuasion Attempts." Journal of Consumer Research 21 (1): 1-31.

Gardner, David M. 1975. “Deception in Advertising: A Conceptual Approach.” Journal of Marketing 39 (1): 40-46.

Goodman, Joseph K, Cynthia E. Cryder, and Amar Cheema. 2013. "Data Collection in a Flat World: The Strengths and Weaknesses of Mechanical Turk Samples.” Journal of Behavioral Decision Making 26 (3): 213-224.

Gopinath, Shyam, Jacquelyn S. Thomas, and Lakshman Krishnamurthi. 2014 "Investigating the Relationship Between the Content of Online Word of Mouth, Advertsing, and brand Performance.” Marketing Science 33 (2) 241-258.

Gruen, Thomas W., Talai Osmonbekov, and Andrew J. Czaplewski. 2006. "EWOM: The Impact of Customer-to-Customer Online Know-How Exchange on Customer Value and Loyalty.” Journal of Business Research 59 (4): 449-456. 
Hajli, M. Nick, Julian Sims, Mauricio Featherman, and Peter E. D. Love. 2015. "Credibility of Information in Online Communities." Journal of Strategic Marketing 23 (3): 238-53.

Hajli, Nick. 2018. "Ethical Environment in the Online Communities by Information Credibility: A Social Media Perspective.” Journal of Business Ethics 149 (4): 799-810.

Hayes, Andrew F. 2018. Introduction to Mediation, Moderation, and Conditional Process Analysis: A Regression-Based Approach (2 $2^{\text {nd }}$ ed.). New York: Guilford Publications. Huang, Liqiang, Jie Zhang, Hefu Liu, and Liang Liang. 2014. "The Effect of Online and Offline Word-of-Mouth on New Product Diffusion.” Journal of Strategic Marketing 22 (2): 177189.

Isen, Alice M., Thomas E. Shalker, Margaret Clark, and Lynn Karp. 1978. “Affect, Accessibility of Material in Memory, and Behavior: A Cognitive Loop?” Journal of Personality and Social Psychology 36 (1): 1-12.

Kahan, Dan M., Ellen Peters, Maggie Wittlin, Paul Slovic, Lisa Larrimore Ouellette, Donald Braman, and Gregory Mandel. 2012. “The Polarizing Impact of Science Literacy and Numeracy on Perceived Climate Change Risks." Nature Climate Change 2 (10): 732-735.

Kareklas, Ioannis, Darrel D. Muehling, and T. J. Weber. 2015. "Reexamining Health Messages in the Digital Age: A Fresh Look at Source Credibility Effects.” Journal of Advertising 44 (2): $88-104$.

Kim, Su Jung, Ewa Maslowska, and Ali Tamaddoni. 2019. "The Paradox of (Dis) Trust in Sponsorship Disclosure: The Characteristics and Effects of Sponsored Online Consumer Reviews." Decision Support Systems 116: 114-124. 
Kim, Su Jung, Ewa Maslowska, and Edward C. Malthouse. 2018. "Understanding the Effects of Different Review Features on Purchase Probability." International Journal of Advertising 37 (1): 29-53.

King, Robert Allen, Pradeep Racherla, and Victoria D. Bush. 2014. "What We Know and Don't Know About Online Word-Of-Mouth: A Review and Synthesis of the Literature." Journal of Interactive Marketing 28 (3): 167-183.

Kirmani, Amna, and Rui Zhu. 2007. "Vigilant Against Manipulation: The Effect of Regulatory Focus on the Use of Persuasion Knowledge.” Journal of Marketing Research 44 (4): 688701.

Koslow, Scott. 2000. "Can the Truth Hurt? How Honest and Persuasive Advertising Can Unintentionally Lead to Increased Consumer Skepticism.” Journal of Consumer Affairs 34 (2): $245-267$.

Kuo, Hsiao-Ching, and Chinintorn Nakhata. 2019. "The Impact of Electronic Word-of-Mouth on Customer Satisfaction.” Journal of Marketing Theory and Practice 27 (3): 331-348.

Kupor, Daniella, and Zakary Tormala. 2018. "When Moderation Fosters Persuasion: The Persuasive Power of Deviatory Reviews." Journal of Consumer Research 45 (3): 490-510.

Lee, Hyun-Hwa, and Yoon Jin Ma. 2012. "Consumer Perceptions of Online Consumer Product and Service Reviews: Focusing on Information Processing Confidence and Susceptibility to Peer Influence.” Journal of Research in Interactive Marketing 6 (2): 110-132.

Li, Xinxin, and Lorin M. Hitt. 2008. "Self-Selection and Information Role of Online Product Reviews." Information Systems Research 19 (4): 456-474. 
Lin, Carolyn A. and Xiaowen Xu. 2017. "Effectiveness of Online Consumer Reviews: The Influence of Valence, Reviewer Ethnicity, Social Distance and Source Trustworthiness." Internet Research 27 (2); 362-380.

Ludwig, Stephan, Ko De Ruyter, Mike Friedman, Elisabeth C. Brüggen, Martin Wetzels, and Gerard Pfann. 2013. "More Than Words: The Influence of Affective Content and Linguistic Style Matches in Online Reviews on Conversion Rates." Journal of Marketing 77 (1): 87103.

Ma, Yoon Jin, and Hyun-Hwa Lee. 2014. "Consumer Responses Toward Online Review Manipulation." Journal of Research in Interactive Marketing 8 (3): 224-244.

Malthouse, Edward C., and Georgios Askalidis. 2015. "From Reviews to Revenue: How Reviewer Self-Selection Impacts Ratings and Reviews." Power Reviews, Northwestern University 2, 1-19.

Manskar, Noah. 2020. "Facebook, eBay pledge Crackdown on Scammers Trading Fake Reviews.” Accessed on January 22, 2020. https://nypost.com/2020/01/08/facebook-ebay-tocrack-down-on-fake-reviews-at-uk-watchdogs-request/

Maslowska, Ewa, Edward C. Malthouse, and Stefan F. Bernritter. 2017. "Too Good to Be True: The Role of Online Reviews’ Features in Probability to Buy." International Journal of Advertising 36 (1): 142-163.

Maslowska, Ewa, Edward C. Malthouse, and Vijay Viswanathan. 2017. "Do Customer Reviews Drive Purchase Decisions? The Moderating Roles of Review Exposure and Price.” Decision Support Systems 98: 1-9. 
Maslowska, Ewa, Claire M. Segijn, Khadija Ali Vakeel, and Vijay Viswanathan. 2019. "How Consumers Attend to Online Reviews: An Eye-Tracking and Network Analysis Approach.” International Journal of Advertising 39 (2): 282-306.

Mathwick, Charla, and Jill Mosteller. 2017. “Online Reviewer Engagement: A Typology Based on Reviewer Motivations.” Journal of Service Research 20 (2): 204-218.

Mayzlin, Dina, Yaniv Dover, and Judith Chevalier. 2014. "Promotional Reviews: An Empirical Investigation of Online Review Manipulation.” American Economic Review 104 (8): 24212455.

Mitra, Anusree, and John G. Lynch Jr. 1995. "Toward a Reconciliation of Market Power and Information Theories of Advertising Effects on Price Elasticity." Journal of Consumer Research 21 (4): 644-659.

Moriuchi, Emi. 2018. "Is That Really an Honest Online Review? The Effectiveness of Disclaimers in Online Reviews.” Journal of Marketing Theory and Practice 26 (3): 309-327.

Mudambi, Susan M., and David Schuff. 2010. "What Makes a Helpful Online Review? A Study of Customer Reviews on Amazon.com." MIS Quarterly 34 (1): 185-200.

Mummolo, Jonathan, and Erik Peterson. 2019. "Demand Effects in Survey Experiments: An Empirical Assessment." American Political Science Review 113 (2): 517-529.

Munzel, Andreas. 2016. "Assisting Consumers in Detecting Fake Reviews: The Role of Identity Information Disclosure and Consensus." Journal of Retailing and Consumer Services 32: 96108.

National Public Radio. 2013. "Top Reviewers on Amazon Get Tons of Free Stuff.” Accessed on September 25, 2019. https://www.npr.org/sections/money/2013/10/29/241372607/top$\underline{\text { reviewers-on-amazon-get-tons-of-free-stuff. }}$ 
NBC. 2019. "How to Spot Fake Product Reviews Online.” NBC Nightly News broadcast, December 19, 2019. https://www.nbcnews.com/nightly-news/video/how-to-spot-fakeproduct-reviews-online-75392581867

Nguyen, Long T., Traci J. Hess, Ying Liu, and Zachary J. Sheffler. 2019. "Trust in Online Reviews: Integrating the Elaboration Likelihood Model and IS Trust." Twenty-fifth Americas Conference on Information Systems, Cancun, 2019.

Nguyen, Nicole. 2019. "Her Amazon Purchases are Real. The Reviews are Fake.” Accessed on January 22, 2020. https://www.buzzfeednews.com/article/nicolenguyen/her-amazonpurchases-are-real-the-reviews-are-fake

Nguyen, Vicky. 2019. "How to Spot Fake Product Reviews Online.” Accessed on January 22, 2020. https://www.nbcnews.com/nightly-news/video/how-to-spot-fake-product-reviews$\underline{\text { online-75392581867 }}$

Obermiller, Carl, and Eric R. Spangenberg. 1998. "Development of a Scale to Measure Consumer Skepticism Toward Advertising.” Journal of Consumer Psychology 7 (2): 159186.

Oppenheimer, Daniel M., Tom Meyvis, and Nicolas Davidenko. (2009). "Instructional Manipulation Checks: Detecting Satisficing to Increase Statistical Power," Journal of Experimental Social Psychology 45 (4): 867-872.

O'Reilly, Kelley, and Sherry Marx. 2011. "How Young, Technical Consumers Assess Online WOM Credibility." Qualitative Market Research: An International Journal 14 (4): 330-359. Pan, Lee-Yun, and Jyh-Shen Chiou. 2011. "How Much Can You Trust Online Information? Cues for Perceived Trustworthiness of Consumer-Generated Online Information.” Journal of Interactive Marketing 25 (2): 67-74. 
Pan, Yue, and Jason Q. Zhang. 2011. "Born Unequal: A Study of the Helpfulness of UserGenerated Product Reviews.” Journal of Retailing 87 (4): 598-612.

Patel, Neil, and Eric Siu. 2019. “Customer Reviews Are Important (Here's How to Get More): Episode 1204.” Accessed on January 22, 2020. https://castbox.fm/episode/Customer$\underline{\text { Reviews-Are-Important-(Here's-How-To-Get-More)-\%7C-Ep.-1204-id363254- }}$ $\underline{\text { id203054676?utm_campaign }=i \_s h a r e \_e p \& u t m \_m e d i u m=d l i n k \& u t m \_s o u r c e=i \_s h a r e \& c o u n t}$ $\underline{\text { ry }=u s}$

Peracchio, Laura A., and Joan Meyers-Levy. 1997. "Evaluating Persuasion-Enhancing Techniques from a Resource-Matching Perspective.” Journal of Consumer Research 24 (2): 178-191.

Picchi, Aimee. 2019. "Buyer Beware: Scourge of Fake Reviews Hitting Amazon, Walmart and other Major Retailers.” Accessed on January 22, 2020. https://www.cbsnews.com/news/buyer-beware-a-scourge-of-fake-online-reviews-is-hittingamazon-walmart-and-other-major-retailers/

Posavac, Steven S., Michal Herzenstein, and David M. Sanbonmatsu. 2003. "The Role of Decision Importance and the Salience of Alternatives in Determining the Consistency Between Consumers' Attitudes and Decisions." Marketing Letters 14 (1): 47-57.

Preston, Ivan L. 2002. “A Problem Ignored: Dilution and Negation of Consumer Information by Antifactual Content.” Journal of Consumer Affairs 36 (2): 263-283.

Purnawirawan, Nathalia, Martin Eisend, Patrick De Pelsmacker, and Nathalie Dens. 2015. “A Meta-analytic Investigation of the Role of Valence in Online Reviews. Journal of Interactive Marketing 31 (1): 17-27. 
Raassens, Néomie, and Hans Haans. 2017. "NPS and Online WOM: Investigating the Relationship Between Customers’ Promoter Scores and EWOM Behavior.” Journal of Service Research 20 (3): 322-334.

Reichelt, Jonas, Jens Sievert, and Frank Jacob. 2014. "How Credibility Affects EWOM Reading:

The Influences of Expertise, Trustworthiness, and Similarity on Utilitarian and Social Functions." Journal of Marketing Communications 20 (1-2): 65-81.

Reputation Defender. 2018. “Online Reputation Management Services for Businesses.” Accessed on September 25, 2019. https://www.reputationdefender.com/business

ReviewMeta. 2016. “Analysis of 7 Million Amazon Reviews: Customers Who Receive Free or Discounted Item Much More Likely to Write Positive Review.” Accessed on January 22, 2020. https://reviewmeta.com/blog/analysis-of-7-million-amazon-reviews-customers-who$\underline{\text { receive-free-or-discounted-item-much-more-likely-to-write-positive-review/ }}$

Roy, Gobinda, Biplab Datta, and Srabanti Mukherjee. 2019 "Role of Electronic Word-of-Mouth Content and Valence in Influencing Online Purchase Behavior." Journal of Marketing Communications 25 (6): 661-684.

Ruan, Na, Ruoyu Deng, and Chunhua Su. 2020. "GADM: Manual Fake Review Detection for O2O Commercial Platforms." Computers \& Security 88: 101657.

Rynarzewska, Ania Izabela. 2019. "It's Not Fake, It's Biased: Insights into Morality of Incentivized Reviewers." Journal of Consumer Marketing 36 (3): 401-409.

Salehan, Mohammad, and Dan J. Kim. 2016. "Predicting the Performance of Online Consumer Reviews: A Sentiment Mining Approach to Big Data Analytics." Decision Support Systems 81: 30-40. 
Sheehan, Kim Bartel, and Matthew Pittman. 2016. Amazon's Mechanical Turkfor Academics:

The HIT Handbook for Social Science Research. Melvin \& Leigh, Publishers.

Smith, Aaron, and Monica Anderson. 2016. “Online Reviews. Pew Research Center: Internet and Technology.” Accessed on September 25, 2019. https://www.pewinternet.org/2016/12/19/online-reviews/

Stanton, Steven J., John Kim, Jennifer C. Thor, and Xiaodong Deng. 2019. "Incentivized Methods to Generate Electronic Word-of-Mouth: Implications for the Resort Industry." International Journal of Hospitality Management 78: 142-149.

Sterling, Greg. 2019. "Consumers Largely Unaware of Fake Reviews Problem on Amazon.” Accessed on January 22, 2020. https://searchengineland.com/consumers-largely-unaware-offake-reviews-problem-on-amazon-315083

Stych, Anne. 2019. “Amazon Expected to Grab 47 Percent of Online Sales.” Biz Women: The Business Journals. Accessed on January 2, 2020. https://www.bizjournals.com/bizwomen/news/latest-news/2019/02/amazon-expected-tograb-47-percent-of-online-sales.html?page=all

Sun, Monic. 2012. "How Does the Variance of Product Ratings Matter?.” Management Science 58 (4): 696-707.

Swearingen, Jake. 2019. “Hijacked Reviews on Amazon can Trick Shopper.” Accessed on September 25, 2019. https://www.consumerreports.org/customer-reviews-ratings/hijacked$\underline{\text { reviews-on-amazon-can-trick-shoppers/ }}$

Tata, Sai Vijay, Sanjeev Prashar, and Sumeet Gupta. 2020. "An Examination of The Role of Review Valence and Review Source in Varying Consumption Contexts on Purchase Decision." Journal of Retailing and Consumer Services 52. 
The UK Rules. 2020. “Fake Online Reviews Illegal or Not?” Accessed on January 25, 2020. https://www.theukrules.co.uk/rules/media/website/fake-reviews.html

Thomas, Kyle A., and Scott Clifford. 2017. "Validity and Mechanical Turk: An Assessment of Exclusion Methods and Interactive Experiments." Computers in Human Behavior 77: 184197.

Thomas, Veronica L., Kendra Fowler, and Pamela Grimm. 2013. “Conceptualization and Exploration of Attitude Toward Advertising Disclosures and Its Impact on Perceptions of Manipulative Intent.” Journal of Consumer Affairs 47 (3): 564-587.

Venkatraman, Vinod, Angelika Dimoka, Paul A. Pavlou, Khoi Vo, William Hampton, Bryan Bollinger, Hal E. Hershfield, Masakazu Ishihara, and Russell S. Winer. 2015. "Predicting Advertising Success Beyond Traditional Measures: New Insights from Neurophysiological Methods and Market Response Modeling." Journal of Marketing Research 52 (4): 436-452. Walsh, Hannah. 2019. “Thousands of 'Fake' Customer Reviews Found on Popular Tech Categories on Amazon.” Accessed on September 25, 2019. https://www.which.co.uk/news/2019/04/thousands-of-fake-customer-reviews-found-onpopular-tech-categories-on-amazon/

Weber, T.J., Darrel D. Muehling, and Ioannis Kareklas. 2019. "How Unsponsored, Online UserGenerated Content Impacts Consumer Attitudes and Intentions Toward Vaccinations." Journal of Marketing Communications: 1-26.

Westbrook, Robert A. 1980. “Intrapersonal Affective Influences on Consumer Satisfaction with Products.” Journal of Consumer Research 7 (1): 49-54. 
Xie, Guang-Xin, Robert Madrigal, and David M. Boush. 2015. "Disentangling the Effects of Perceived Deception and Anticipated Harm on Consumer Responses to Deceptive Advertising." Journal of Business Ethics 129 (2): 281-293.

Yang, Jing, Rathindra Sarathy, and JinKyu Lee. 2016. “The Effect of Product Review Balance and Volume on Online Shoppers' Risk Perception and Purchase Intention.” Decision Support Systems 89: 66-76.

You, Ya, Gautham G. Vadakkepatt, and Amit M. Joshi. 2015. “A Meta-Analysis of Electronic Word-of-Mouth Elasticity." Journal of Marketing 79 (2): 19-39.

Zax, David, and David Zax. 2017. "The War to Sell You a Mattress is an Internet Nightmare." Accessed on September 25, 2019. https://www.fastcompany.com/3065928/sleepopoliscasper-bloggers-lawsuits-underside-of-the-mattress-wars.

Zhang, Dongsong, Lina Zhou, Juan Luo Kehoe, and Isil Yakut Kilic. 2016. "What Online Reviewer Behaviors Really Matter? Effects of Verbal and Nonverbal Behaviors on Detection of Fake Online Reviews." Journal of Management Information Systems 33 (2): 456-481.

Zhang, Lu. 2015. “Online Reviews: The Impact of Power and Incidental Similarity.” Journal of Hospitality Marketing \& Management 24 (6): 633-651.

Zhang, Xiao Jerry, Myung Ko, and Darrell Carpenter. 2016. "Development of a Scale to Measure Skepticism Toward Electronic Word-of-Mouth." Computers in Human Behavior 56: 198-208. 


\section{APPENDIX A}

Study 1 Stimuli

Overall Customer Rating

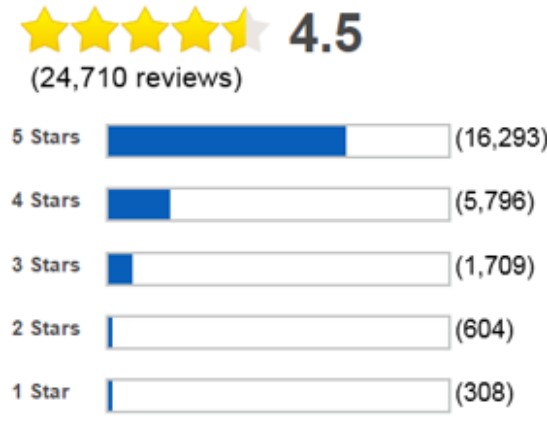

Whitebird Electric Toothbrush

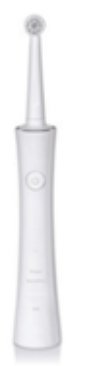

PRICE: \$34.99 \& Free shipping

In stock.

Usually ships in 3 to 4 days.

- Clinically proven superior 3D cleaning.

- Sweeps side to side and pulsates to remove up

to $100 \%$ more plaque than manual toothbrushes.

Overall Customer Rating

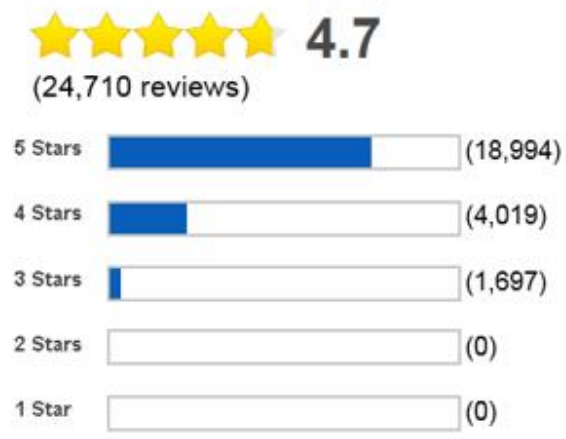

Whitebird Electric Toothbrush



PRICE: \$34.99 \& Free shipping

In stock.

Usually ships in 3 to 4 days.

- Clinically proven superior 3D cleaning.

- Sweeps side to side and pulsates to remove up

to $100 \%$ more plaque than manual toothbrushes.

Overall Customer Rating

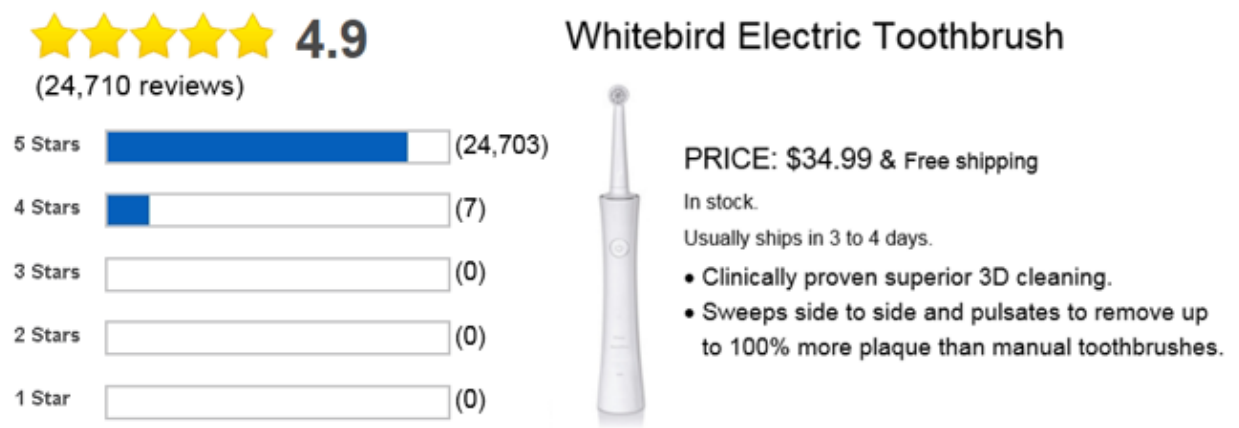

Note: the volume/number of reviews was held constant across conditions, as a means of isolating the effects of 4.5, 4.7 and 4.9 star-ratings. 


\section{APPENDIX B}

\section{Measures}

Purchase intention (adapted from Ajzen and Fishbein 1980): What is the likelihood that you would purchase the product shown the next time you are in the market for an electric toothbrush? $(1=$ unlikely, 7 = likely; 1 = improbable, 7 = probable, $1=$ impossible, $7=$ possible)

Attitude toward the product (adapted from Peracchio and Meyers-Levy 1997): I believe this product is: (1 $=$ mediocre, $7=$ exceptional; $1=$ not at all high quality, $7=$ high quality; $1=$ poorly made, $7=$ well made; $1=$ boring, 7 = exciting; $1=$ not worthwhile, $7=$ worthwhile; $1=$ unappealing, $7=$ appealing; $1=$ poor value, $7=$ excellent value)'

Manipulative intent (adapted from Campbell 1995): Please indicate the extent to which you agree or disagree with the following statements: $(1=$ strongly disagree, $7=$ strongly agree $)$ The way the Star Ratings try to persuade potential consumers seems acceptable to me (r)

- The Star Ratings try to manipulate potential consumers in ways that I don't like

- I was annoyed by the Star Ratings because they seemed to be trying to inappropriately manage or control potential consumers

- I didn't mind the Star Ratings; they tried to be persuasive without being excessively manipulative (r)

- The Star Ratings were fair in their evaluation of the product (r)

- I think the Star Ratings were unfair

(Augmented manipulative intent measure used in Study 2 included six additional items adapted from Flanagin and Metzger 2000, assessing perceptions of the star ratings, reverse coded): ( $1=$ not trustworthy, $7=$ trustworthy; $1=$ not credible, $7=$ credible; $1=$ biased, $7=$ not biased; $1=$ not believable, $7=$ believable; $1=$ unreliable, $7=$ reliable; $1=$ untruthful, $7=$ truthful $)$

Study 1:

Manipulation- check questions: In the screenshot from a retailer's web page that you viewed, what was the Average Star Rating (out of 5 stars) that was reported? $(4.5,4.7,4.9)$

What was the topic of the article (commentary) you read at the beginning of this survey? (Autonomous cars, Authenticity of online reviews)

Attention-check question (The following statement was disguised as an item at the end of the manipulative intent measure): Please select "somewhat agree" for this item.

Study 2:

Manipulation-check questions: Did the screenshot from a retailer's web page that you viewed include a customer star rating? (Yes / No)

In the screenshot from a retailer's web page that you viewed, what was the Average Star Rating (out of 5 stars) that was reported? $(4.5,5.0)$

What was the topic of the article (commentary) you read at the beginning of this survey? (Autonomous cars, Authenticity of online reviews)

Attention-check question (The following statement was disguised as an item at the end of the manipulative intent measure): Please select "somewhat agree" for this item. 


\section{APPENDIX C}

Study 2 Stimuli

Overall Customer Rating



\section{Whitebird Electric Toothbrush}

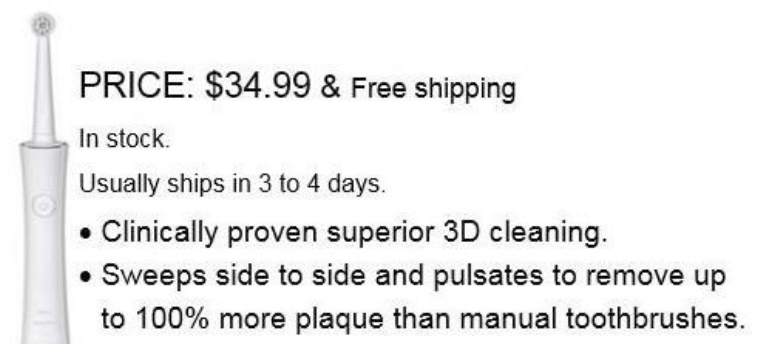

Overall Customer Rating



\section{Whitebird Electric Toothbrush}

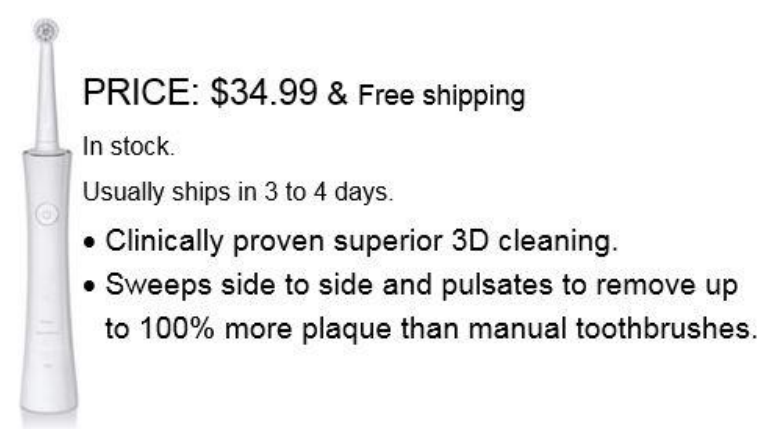

Note: the volume/number of reviews was held constant across conditions, as a means of isolating the effects of 4.5 and 5.0 star-ratings. 


\section{FIGURE 1}

Valence by Awareness Interactions on Attitude Toward the Product and Purchase Intentions (Study 1)
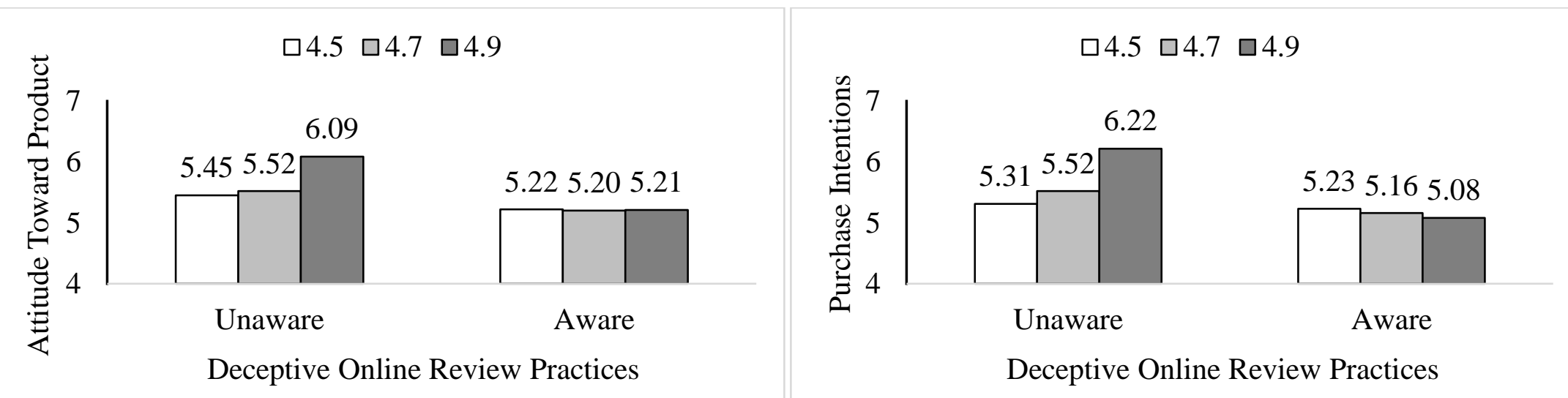

Interaction: $F(2,284)=2.68, p=.07$

Interaction: $F(2,284)=3.22, p<.05$

$\square 4.5 \square 4.7 \square 4.9$

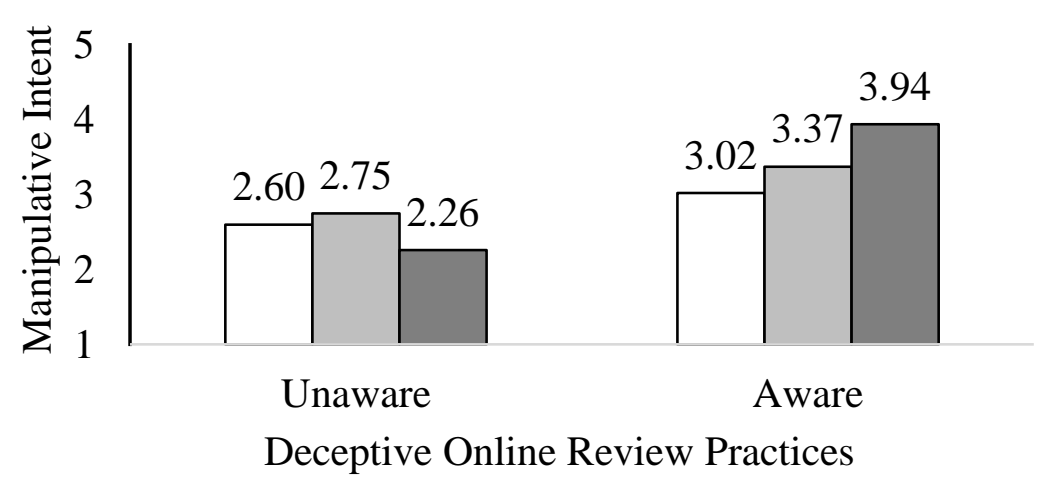

Interaction: $F(2,284)=7.47, p<.001$ 
FIGURE 2

Valence x Awareness Interaction on Attitude and Purchase Intentions through Manipulative Intent (Study 1)



Note: $* * p<.01, * * * p<.001$.

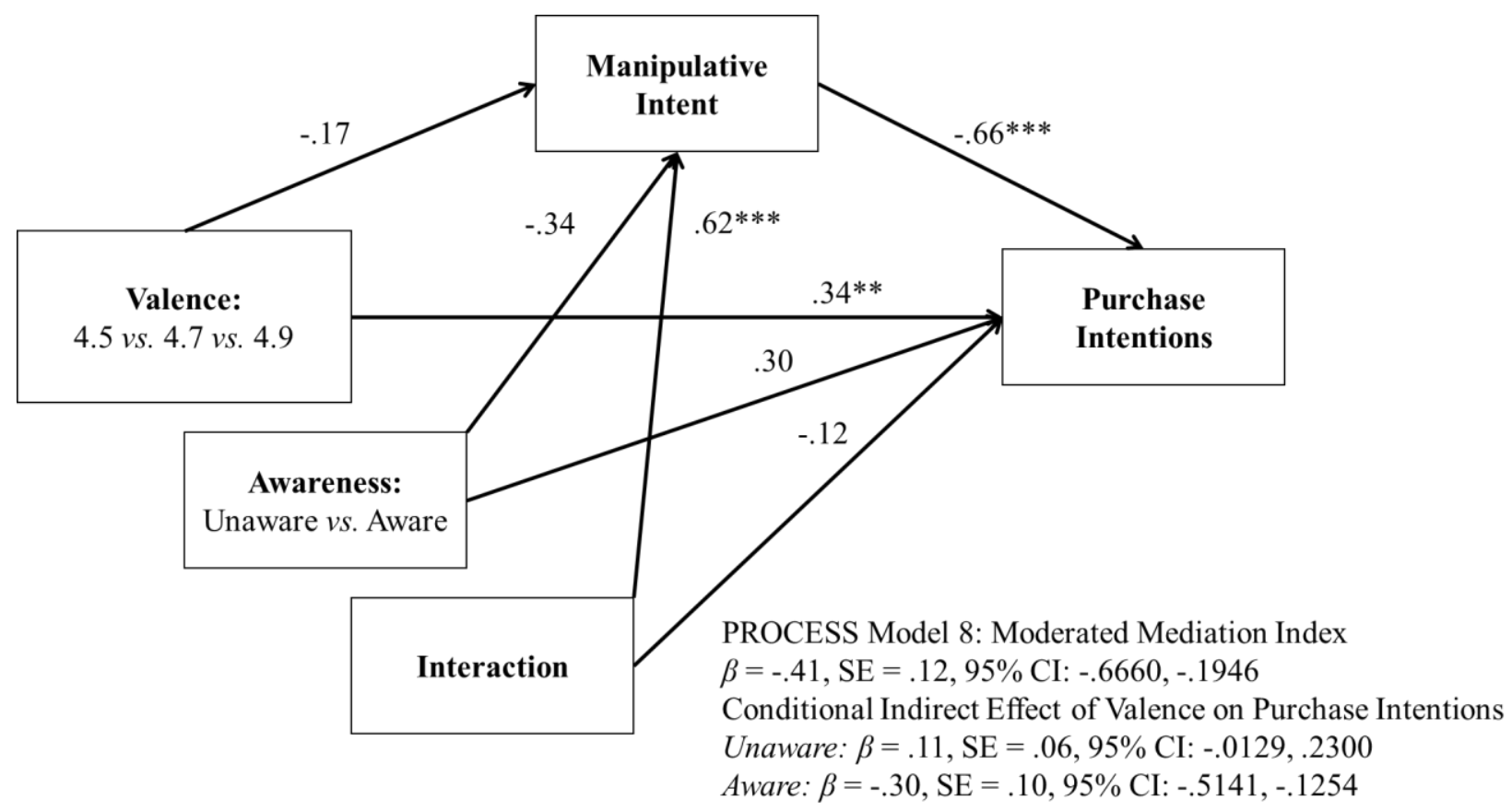

Note: $* * p<.01, * * * p<.001$. 
FIGURE 3

Valence by Awareness Interactions on Attitude Toward the Product and Purchase Intentions (Study 2)

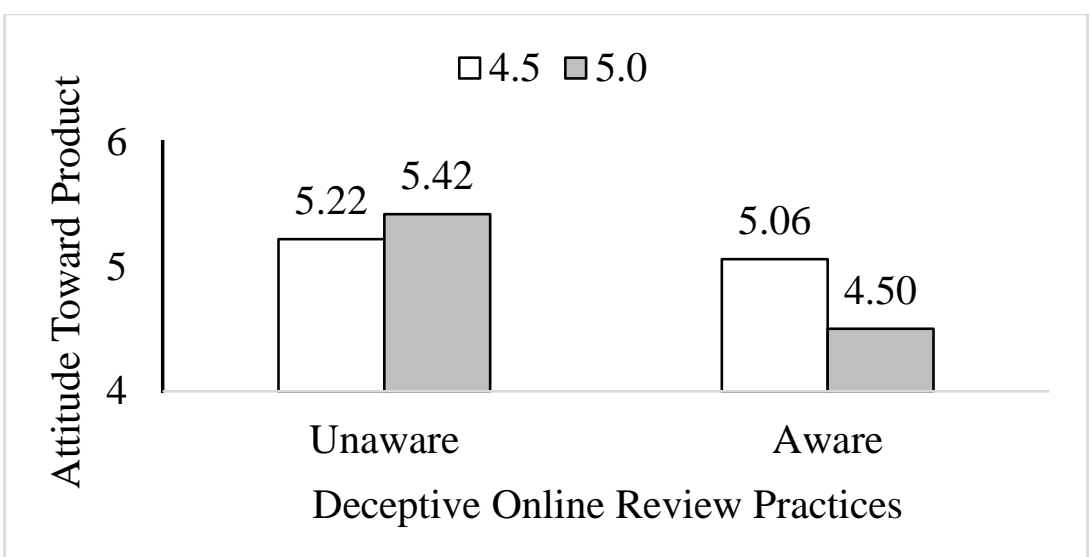

Interaction: $F(1,310)=6.86, p<.01$

\section{$\square 4.5 \square 5.0$}

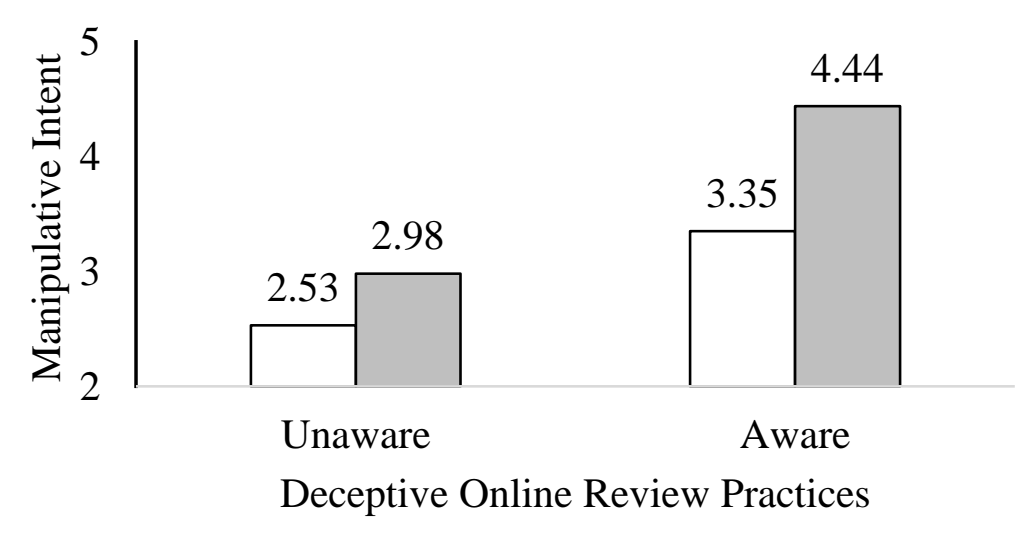

Interaction: $F(1,310)=4.03, p<.05$



Interaction: $F(1,310)=13.30, p<.001$ 
FIGURE 4

Valence x Awareness Interaction on Attitude and Purchase Intentions through Manipulative Intent (Study 2)



Note: $* p<.05, * * * p<.001$.

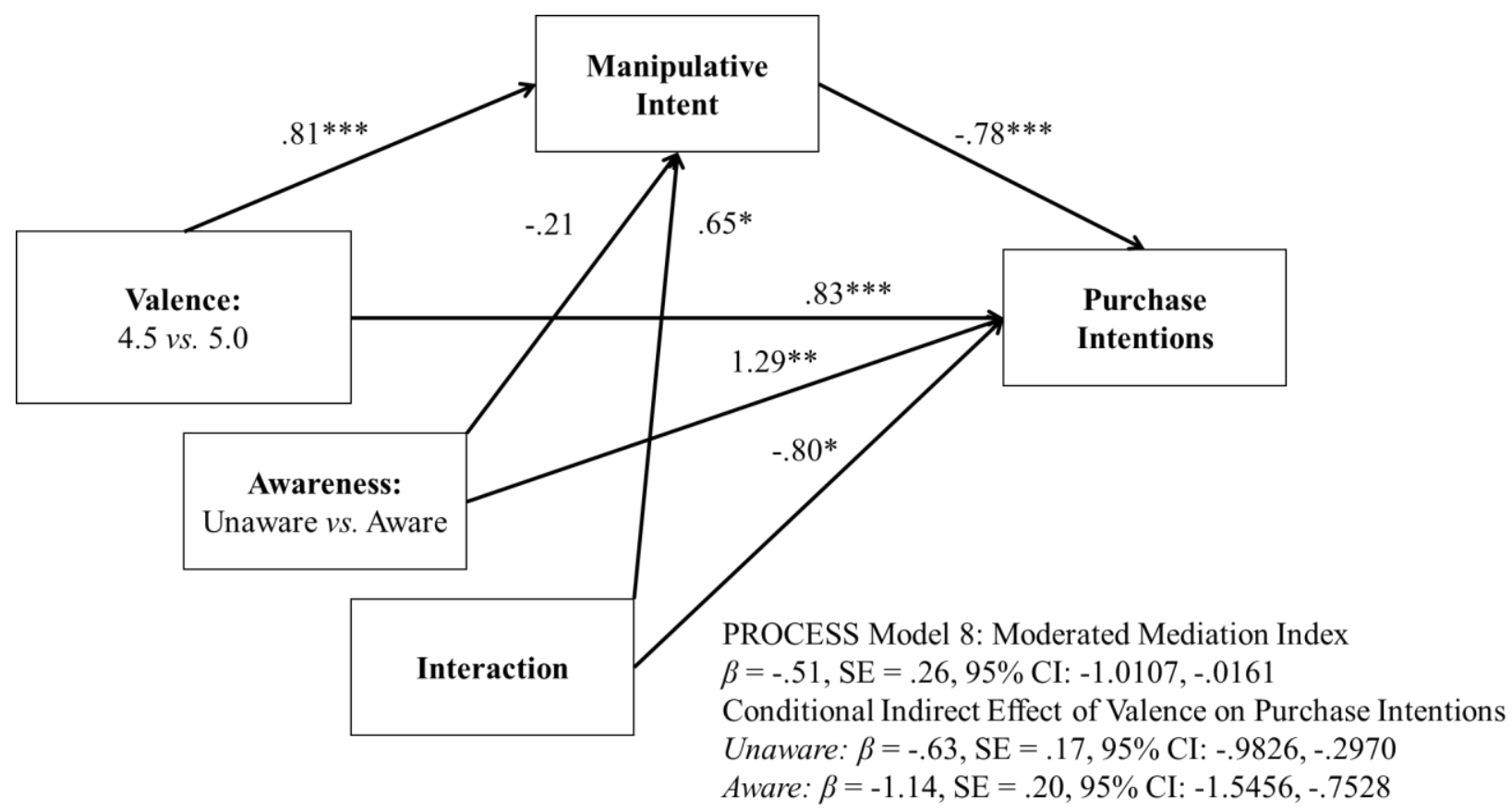

Note: $* p<.05, * * * p<.001$. 
TABLE 1

Consumer Perceptions of the Ethicality of Online Review Practices

\begin{tabular}{|l|c|c|c|}
\hline \multirow{2}{*}{ Scenarios } & \multicolumn{2}{|c|}{ Ethicality } \\
\cline { 2 - 4 } & $\boldsymbol{M}$ & $\boldsymbol{S D}$ & $\boldsymbol{T}$ \\
\hline An online retailer offering a free product in exchange for reviewing the product & $3.79^{*}$ & 1.71 & -1.71 \\
\hline An online retailer posting a review from a product manufacturer on the e-retailer's site & $3.36^{* * *}$ & 1.63 & -5.53 \\
\hline An online retailer paying money to consumers to post reviews for products on their site & $2.29^{* * *}$ & 1.56 & -15.43 \\
\hline An online retailer deleting negative or mixed reviews to maintain a high average review rating & $1.89^{* * *}$ & 1.51 & -19.61 \\
\hline
\end{tabular}

*Mean values compared to scale midpoint (4.0). Endpoints, $1=$ very unethical business practices; $7=$ very ethical business practices. $* p<.05 ; * * * p<.001$ 
TABLE 2

Studies 1 and 2: Descriptive Statistics and Correlation Matrix

\begin{tabular}{llccccc}
\hline \multicolumn{1}{c}{ Study 1 } & & & & & \\
\hline & & $\mathrm{M}$ & $\mathrm{SD}$ & 1 & 2 & 3 \\
1 & Perceived Manipulative Intent & 3.02 & 1.31 & - & & \\
2 & Attitude & 5.85 & 1.18 & $-.58^{* *}$ & - & \\
3 & Purchase Intentions & 5.40 & 1.53 & $-.55^{* *}$ & $.75^{* *}$ & - \\
& & & & & \\
\hline & Study 2 & & & & & \\
\hline & & $\mathrm{M}$ & 1 & 2 & 3 \\
1 & Perceived Manipulative Intent & 3.15 & 1.58 & - & & \\
2 & Attitude & 5.41 & 1.53 & $-.67^{* *}$ & - & \\
3 & Purchase Intentions & 5.18 & 1.65 & $-.64^{* *}$ & $.89^{* *}$ & - \\
\hline
\end{tabular}

Note. $N_{\text {study } 1}=290 ; N_{\text {study } 2}=314 . * * p<.01$ (two-tailed). 
TABLE 3

Study 1: Effect of Valence by Awareness Interaction on Outcome Variables $(\mathbf{N}=290)$

\begin{tabular}{|c|c|c|c|c|c|c|c|c|c|c|c|c|c|}
\hline \multirow{4}{*}{ Dependent Measures } & \multirow[b]{4}{*}{$\boldsymbol{F}$} & \multirow{2}{*}{\multicolumn{6}{|c|}{ Unaware }} & \multirow{2}{*}{\multicolumn{6}{|c|}{ Aware }} \\
\hline & & & & & & & & & & & & & \\
\hline & & \multicolumn{2}{|c|}{4.5} & \multicolumn{2}{|c|}{4.7} & \multicolumn{2}{|c|}{4.9} & \multicolumn{2}{|c|}{4.5} & \multicolumn{2}{|c|}{4.7} & \multicolumn{2}{|c|}{4.9} \\
\hline & & $M$ & $S D$ & $M$ & $S D$ & $M$ & $S D$ & $M$ & $S D$ & $M$ & $S D$ & $M$ & $S D$ \\
\hline Manipulative Intent & $7.47 * * *$ & $2.60^{\mathrm{a}}$ & .97 & $2.75^{\mathrm{a}}$ & 1.34 & $2.26^{\mathrm{a}}$ & .88 & $3.02^{\mathrm{ab}}$ & .89 & $3.37^{\mathrm{b}}$ & 1.27 & $3.94^{\mathrm{c}}$ & 1.66 \\
\hline Attitude toward Product & $2.68^{z}$ & $5.45^{\mathrm{a}}$ & .92 & $5.52^{\mathrm{a}}$ & .97 & $6.09^{b}$ & .86 & $5.22^{\mathrm{a}}$ & .98 & $5.20^{\mathrm{a}}$ & 1.04 & $5.21^{\mathrm{a}}$ & 1.30 \\
\hline Purchase Intentions & $3.22 *$ & $5.31^{\mathrm{a}}$ & 1.58 & $5.52^{\mathrm{a}}$ & 1.49 & $6.22^{b}$ & .95 & $5.23^{\mathrm{a}}$ & 1.47 & $5.16^{\mathrm{a}}$ & 1.55 & $5.08^{\mathrm{a}}$ & 1.78 \\
\hline
\end{tabular}

Note: Using LSD, means are significantly different (at $p<.05)$ if they do not share a superscript. Means are to be compared across rows, separately for each dependent variable. This table shows differences between the valence conditions within the conditions of awareness, as well as differences between the conditions of awareness within the conditions of valence.

$M:$ Mean, SD: Standard Deviation

$d f:(2,284)$

$* p<.05 ; * * * p<.001 ; \mathrm{z}=.07$ 
TABLE 4

Study 2: Effect of Valence by Awareness Interaction on Outcome Variables $(\mathbf{N}=314)$

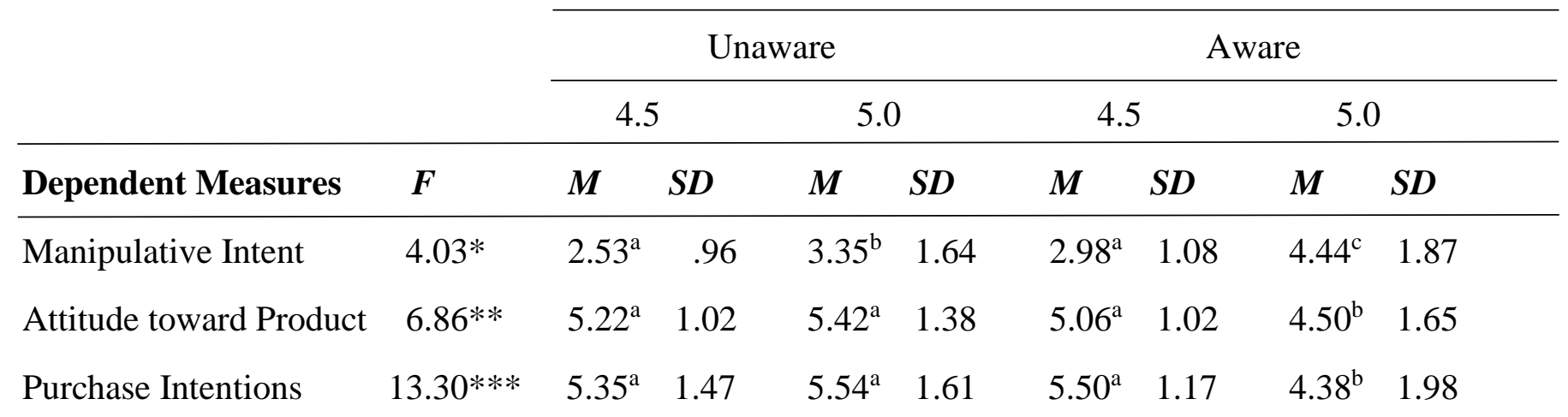

Note: Using LSD, means are significantly different (at $p<.05)$ if they do not share a superscript. Means are to be compared across rows, separately for each dependent variable. This table shows differences between the valence conditions within the conditions of awareness, as well as differences between the conditions of awareness within the conditions of valence.

$M:$ Mean, SD: Standard Deviation

$d f:(1,310)$

${ }^{*} p<.05 ; * * p<.01 ; * * * p<.001$ 